\title{
‡USGS
}

science for a changing world

\section{How to Build and Teach with QuakeCaster-An Earthquake Demonstration and Exploration Tool}

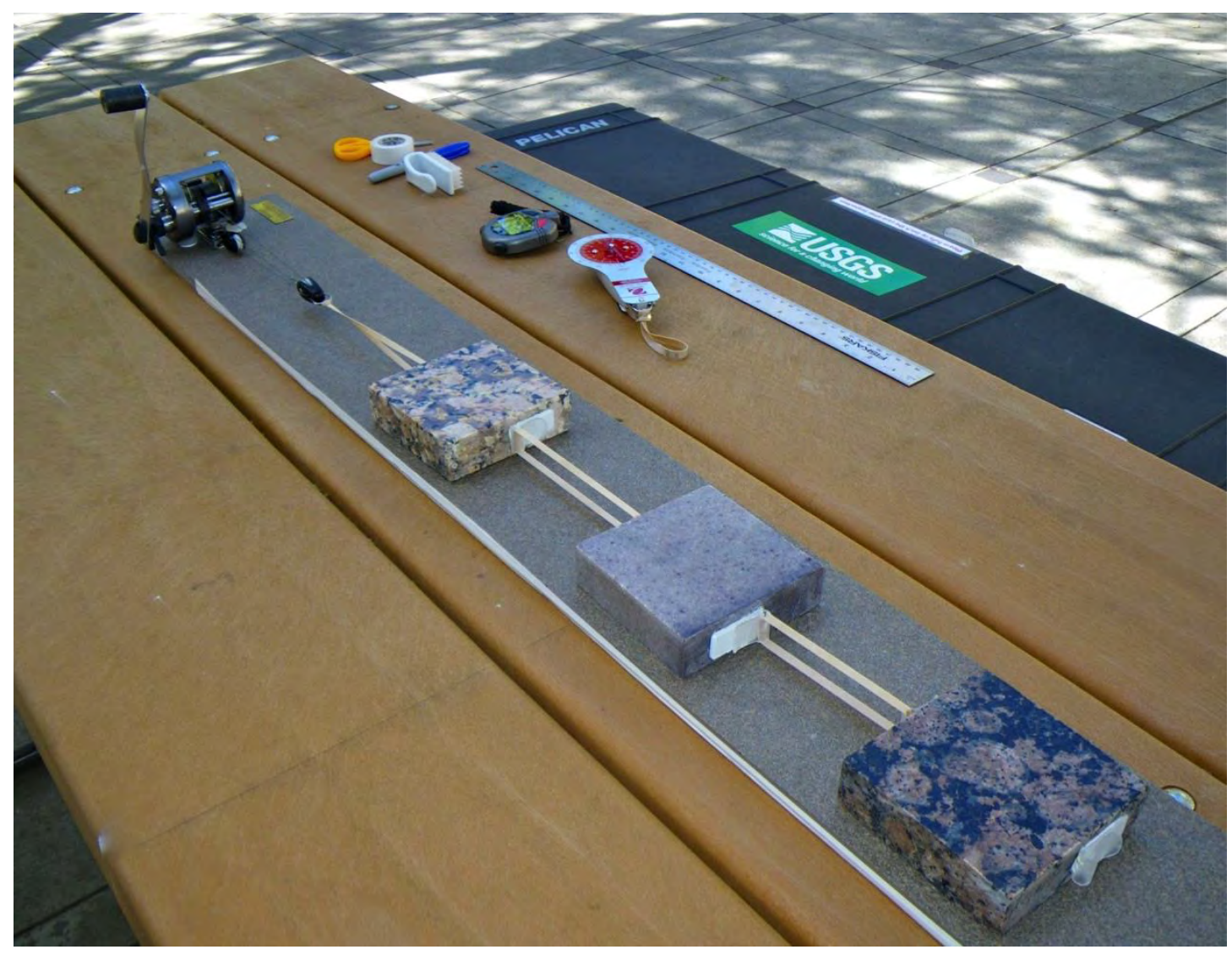

Open-File Report 2011-1158

Version 1.1, March 2015

U.S. Department of the Interior

U.S. Geological Survey 
Photograph of the QuakeCaster mechanism. 


\section{How to Build and Teach with QuakeCaster-An Earthquake Demonstration and Exploration Tool}

By Kelsey Linton and Ross S. Stein

Open-File Report 2011-1158

Version 1.1, March 2015

U.S. Department of the Interior

U.S. Geological Survey 


\section{U.S. Department of the Interior \\ SALLY JEWELL, Secretary}

\section{U.S. Geological Survey \\ Suzette M. Kimball, Acting Director}

U.S. Geological Survey, Reston, Virginia: 2015

First release: 2011

Revised: March 2015 (ver. 1.1)

For more information on the USGS—-the Federal source for science about the Earth, its natural and living resources, natural hazards, and the environment-visit http://www.usgs.gov/ or call 1-888-ASK-USGS (1-888-275-8747).

For an overview of USGS information products, including maps, imagery, and publications, visit http://www.usgs.gov/pubprod/.

Any use of trade, firm, or product names is for descriptive purposes only and does not imply endorsement by the U.S. Government.

Although this information product, for the most part, is in the public domain, it also may contain copyrighted materials as noted in the text. Permission to reproduce copyrighted items must be secured from the copyright owner.

Suggested citation:

Linton, K., and Stein, R.S., 2015, How to build and teach with QuakeCaster-An earthquake demonstration and exploration tool (ver. 1.1, March 2015): U.S. Geological Survey Open-File Report 2011-1158, 38 p. and videos, http://dx.doi.org/10.3133/ofr20111158.

ISSN 2331-1258 (online) 


\section{Contents}

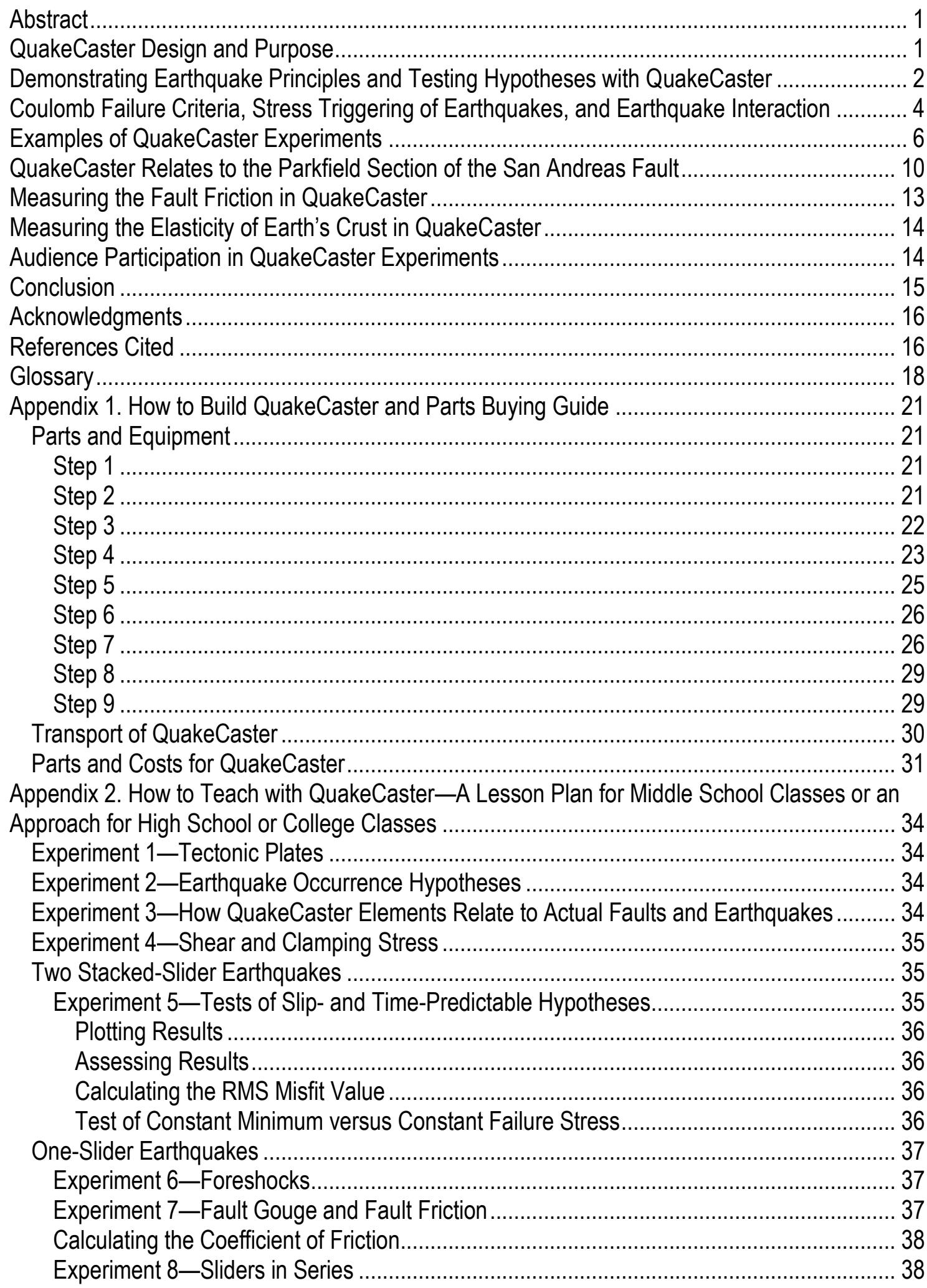




\section{Figures}

Figure 1. Graphs of expected behavior under three earthquake hypotheses ..............................

Figure 2. Graphs of fault stress versus time …………….................................................

Figure 3. Photographs of the QuakeCaster mechanism .........................................................

Figure 4. Graphs of test trials of the slip-predictable and time-predictable hypotheses. ..............7

Figure 5. Graphs of test trials of constant minimum and constant failure stress .........................9

Figure 6. Graphs comparing QuakeCaster and a laboratory experiment on failure stress .........10

Figure 7. Graphs of time and slip predictability in QuakeCaster and at Parkfield, California.......12

Figure 8. Photograph of a student using the QuakeCaster mechanism ....................................13

Figure 9. Photographs of students using the QuakeCaster mechanism...................................14

Figure 10. Photographs of the QuakeCaster mechanism....................................................15

\section{Supplementary Videos}

[Available online only at http://pubs.usgs.gov/of/2011/1158/; includes files for the visually and hearing impaired]

Video 1. Trailer (3 minutes) video that shows QuakeCaster in action and lets you see how you could use it as a teaching tool.

Video 2. Full video (11 minutes) that shows QuakeCaster in action and lets you see how you could use it as a teaching tool. 


\title{
How to Build and Teach with QuakeCaster-An Earthquake Demonstration and Exploration Tool
}

\author{
By Kelsey Linton ${ }^{1}$ and Ross S. Stein²
}

\begin{abstract}
QuakeCaster is an interactive, hands-on teaching model that simulates earthquakes and their interactions along a plate-boundary fault. QuakeCaster contains the minimum number of physical processes needed to demonstrate most observable earthquake features. A winch to steadily reel in a line simulates the steady plate tectonic motions far from the plate boundaries. A granite slider in frictional contact with a nonskid rock-like surface simulates a fault at a plate boundary. A rubber band connecting the line to the slider simulates the elastic character of the Earth's crust. By stacking and unstacking sliders and cranking in the winch, one can see the results of changing the shear stress and the clamping stress on a fault. By placing sliders in series with rubber bands between them, one can simulate the interaction of earthquakes along a fault, such as cascading or toggling shocks. By inserting a load scale into the line, one can measure the stress acting on the fault throughout the earthquake cycle. As observed for real earthquakes, QuakeCaster events are not periodic, time-predictable, or slip-predictable. QuakeCaster produces rare but unreliable "foreshocks." When fault gouge builds up, the friction goes to zero and fault creep is seen without large quakes. QuakeCaster events produce very small amounts of fault gouge that strongly alter its behavior, resulting in smaller, more frequent shocks as the gouge accumulates. QuakeCaster is designed so that students or audience members can operate it and record its output. With a stopwatch and ruler one can measure and plot the timing, slip distance, and force results of simulated earthquakes. People of all ages can use the QuakeCaster model to explore hypotheses about earthquake occurrence. QuakeCaster takes several days and about $\$ 500.00$ in materials to build.
\end{abstract}

\section{QuakeCaster Design and Purpose}

QuakeCaster is composed of a 4-foot-long nonskid-covered foam board with a fishing reel attached at one end. One to three granite blocks, called "sliders," are placed at the opposite end of the tile. The sliders are joined by a rubber band. The fishing line, made of Spectra, is reeled in steadily to the opposite end of the tile and a rubber band joins the line with the first slider. This super-low stretch Spectra line is essentially inelastic at these small loads. The rubber band represents the elasticity of the Earth's

\footnotetext{
${ }^{1}$ Menlo High School, Atherton, California, when originally written; now at Duke University.

${ }^{2}$ U.S. Geological Survey.
} 
crust. The fishing reel is oriented so that the force acting on the sliders is horizontal, which means that the line exerts only shear stress on the slider/plate-boundary fault system. When the fishing reel is cranked at a constant rate, simulating constant tectonic plate velocity, stress will accumulate due to the friction between the sliders and the nonskid-covered foam board. This represents the stress buildup on faults.

Students and the audience can be actively involved in the earthquake experiments. They are able to measure the time between events, the slip distance (which represents earthquake size), force before an event occurs, and force after an event occurs. Despite being a relatively simple model, QuakeCaster is remarkably true to observed earthquake behavior. Thus, students will get a memorable hands-on look at fault stress and fault rupture in the laboratory, and they will understand why it is so difficult to predict earthquakes in the real world. The size of an earthquake is measured by the seismic moment, which is the fault contact area (here, the $4 \times 4$-inch slider surface), times the elastic stiffness (here the stiffness of the rubber band), times the amount of slip (which can be measured in the experiments). The magnitude of an earthquake is proportional to the logarithm of the seismic moment. How to build QuakeCaster and the parts needed are described in appendix 1. Appendix 2 describes how to teach with QuakeCaster.

\section{Demonstrating Earthquake Principles and Testing Hypotheses with QuakeCaster}

A fundamental riddle of earthquake occurrence is that at plate interiors, the tectonic motions are steady, changing only subtly over millions of years. However, at plate-boundary faults, the plates are stuck for hundreds of years and then suddenly jerk forward in earthquakes. Why does this happen? The answer, as formulated by Harry F. Reid in 1910 (Reid, 1910) is that the Earth's crust is elastic - behaving like a very stiff slab of rubber sliding over a substrate of "honey." The crust near the plate-boundary fault is deformed by the plate motion until the stress acting on the fault overcomes the frictional resistance and the fault suddenly slips. For the past century, scientists have sought ways to use this knowledge to predict earthquakes. The four leading earthquake prediction hypotheses, which trend from the most uniform and regular fault behavior to the most irregular and unpredictable, can be tested with QuakeCaster.

Hypothesis 1: Earthquakes are periodic. This means that the same amount of fault slip is separated by the same amount of time. There is some evidence for this, particularly in the study of the data of very small earthquakes on creeping faults (Schwartz and Coppersmith, 1984) (fig. 1A).

Hypothesis 2: Earthquakes are time-predictable. This means that the larger the amount of fault slip in the last earthquake, the longer the time until the next earthquake. (Shimazaki and Nakata, 1980) (fig. 1B). Another way of stating this hypothesis is that earthquakes occur when the failure stress is reached. This means that when a certain amount of stress accumulates along a fault, an earthquake will occur (fig. 2A).

Hypothesis 3: Earthquakes are slip-predictable. This means that the longer the time stress accumulates, the greater the amount of fault slip in the next earthquake (fig. 1C). Another way of stating this hypothesis is that earthquakes decrease the 
amount of stress along a fault to a fixed minimum or to a background amount (Bufe and others, 1977) (fig. 2B).

Hypothesis 4: Earthquakes occur randomly and have randomly varying size. This 'Poisson' hypothesis is also widely used, particularly when little information about a fault and its past earthquakes is available (Campbell, 1982).
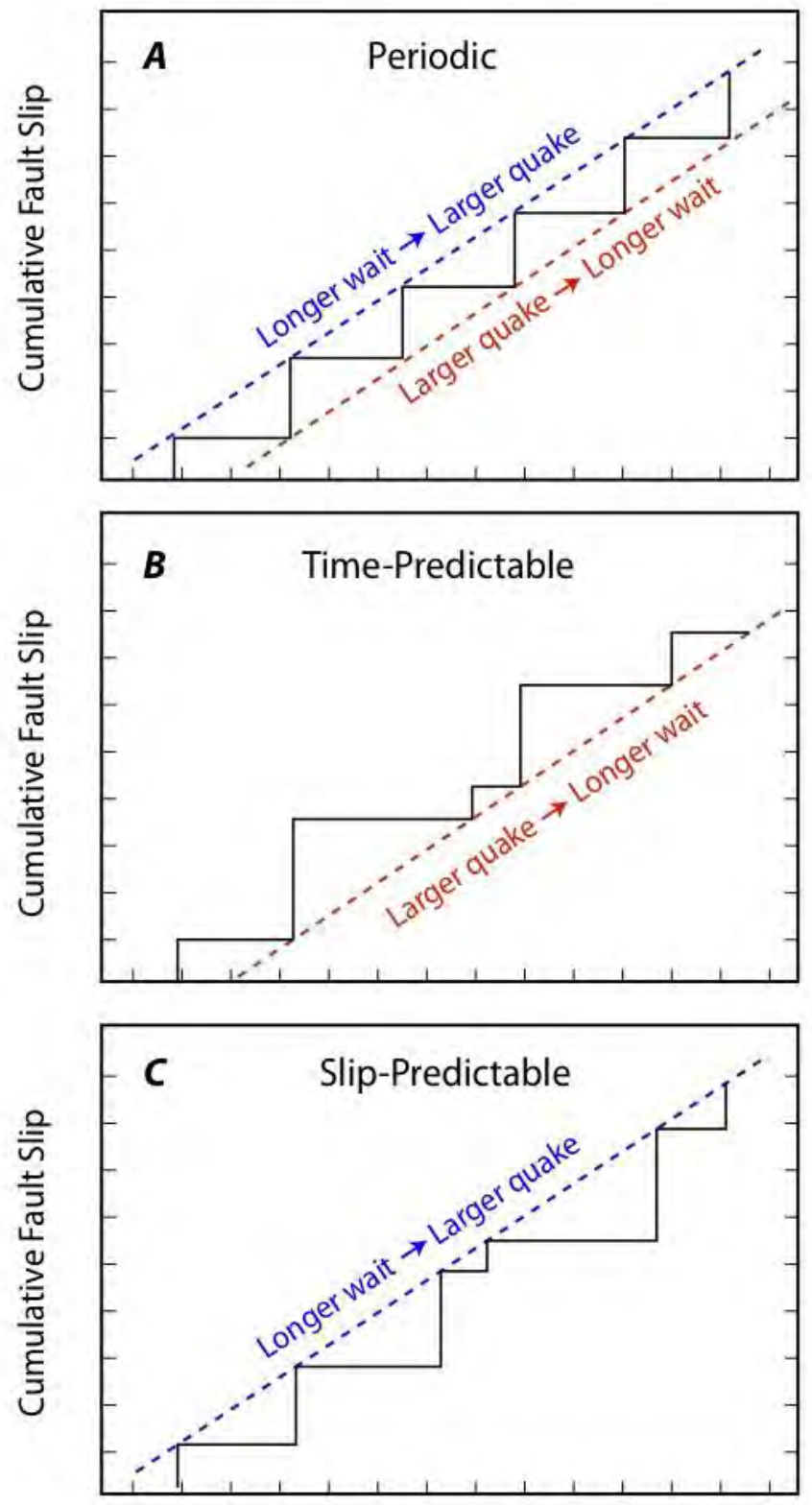

Cumulative Time

Figure 1. Graphs of expected behavior under three earthquake hypotheses. $A$, The top chart illustrates what we would expect to see if earthquakes were periodic. $B$, The middle chart illustrates 
what we would expect to see if earthquakes were time-predictable. $C$, The bottom chart illustrates what we would expect to see if earthquakes were slip-predictable. Blue dashed line represents best fit with slip-predictable hypothesis. Red dashed line represents best fit with time-predictable hypothesis.
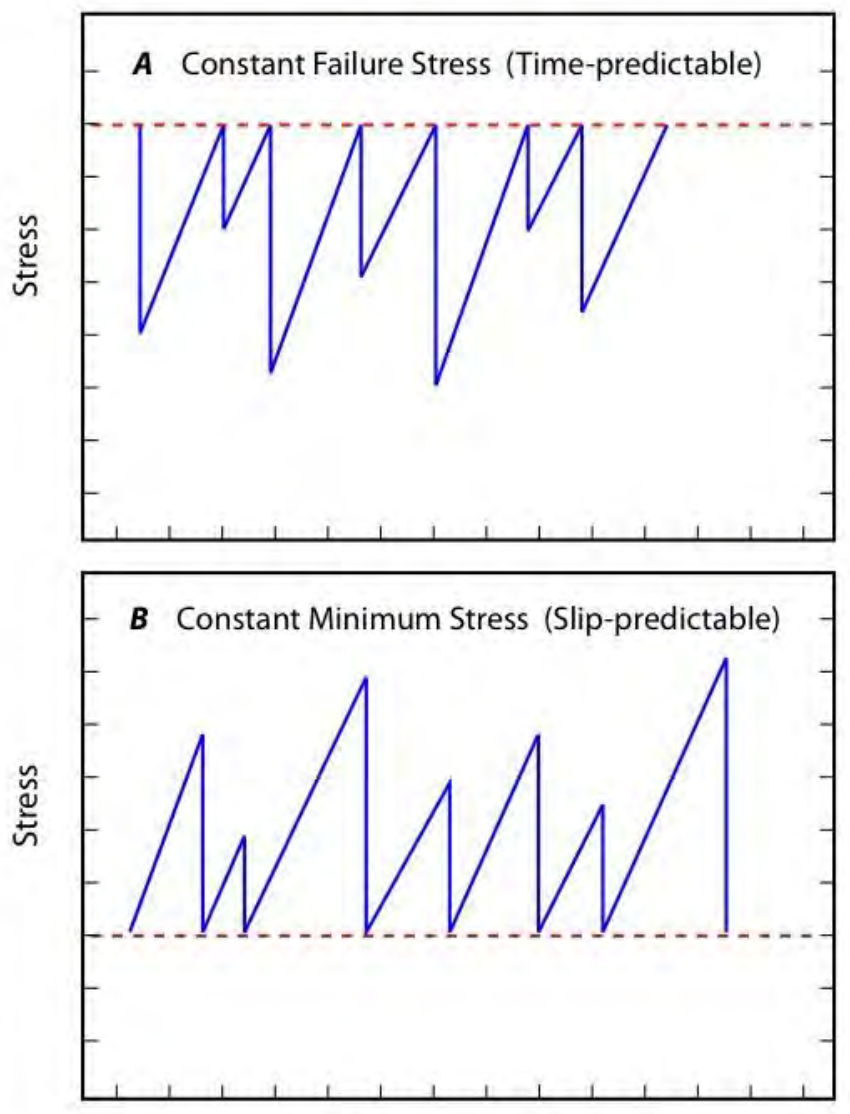

Cumulative Time

Figure 2. Graphs of fault stress versus time. Failure and minimum stress hypotheses are variations of the slip-predictable and time-predictable hypotheses, but they are stated in terms of fault stress rather than in terms of fault slip. The slope of the diagonal lines is the fault-stressing rate; these lines are imperfectly parallel because hand-cranking results in slight variations in fault stress loading rate. A, QuakeCaster data similar to this record would suggest that the minimum stress is the best indicator of earthquakes because failure stress is too variable. B, QuakeCaster data similar to this record would suggest that the minimum stress is the best indicator of earthquakes because failure stress is too variable.

\section{Coulomb Failure Criteria, Stress Triggering of Earthquakes, and Earthquake Interaction}

QuakeCaster can demonstrate Coulomb failure criteria, which holds that when a fault is close to failure, either increasing the shear stress (by reeling in a bit more line) or 
decreasing friction by reducing fault clamping (often termed "normal"), stress will promote fault failure. To demonstrate increasing the shear stress, stack two sliders, and reel in the line until the two sliders are on the verge of slipping. Now crank a bit more to trigger an earthquake. To demonstrate reducing fault clamping, reel in the line again until the slider is on the verge of slipping, and lift the top slider. Again it will trigger an earthquake. If the static-friction coefficient of the fault is about 0.5 , then increasing the shear stress will have twice the impact as unclamping the fault in triggering an earthquake. The Coulomb hypothesis and the concept of stress triggering of earthquakes are explained in plain English in Stein (2003).

QuakeCaster can also demonstrate how earthquakes interact by the transfer of stress along a fault (fig. $3 A$ ). We define shear stress as the force divided by the surface area. In QuakeCaster, when the force builds up to 1,000 grams, one $4 \times 4$-inch slider has a shear stress of roughly 0.96 kilopascal $(\mathrm{kPa})$. With the QuakeCaster model, because the surface area is constant, we can look at force alone. One QuakeCaster experiment that demonstrates stress triggering involves adding a second slider behind the first. The sliders are joined by a rubber band. When stress overcomes the frictional resistance on the fault, the first slider moves forward, which increases the stress on the second slider. Eventually, the second slider moves forward, reducing the restraining force on the first slider, and the first slider moves forward again. We ask the audience to predict which slider will move first, second, third, and fourth. Observers are almost always surprised by the outcome (which changes somewhat from one trial to the next). By making a prediction of their own, they become invested in the outcome and more curious about earthquake interaction along a fault.

Additional accessories can be used to enhance the audience's understanding of earthquake behavior. A ruler can be used to measure the amount of fault slip during earthquakes, a lap-timer stopwatch can measure the time between earthquakes, and a fishscale (a small dial scale) can be used to measure the force buildup on a fault (fig. $3 B$ ).
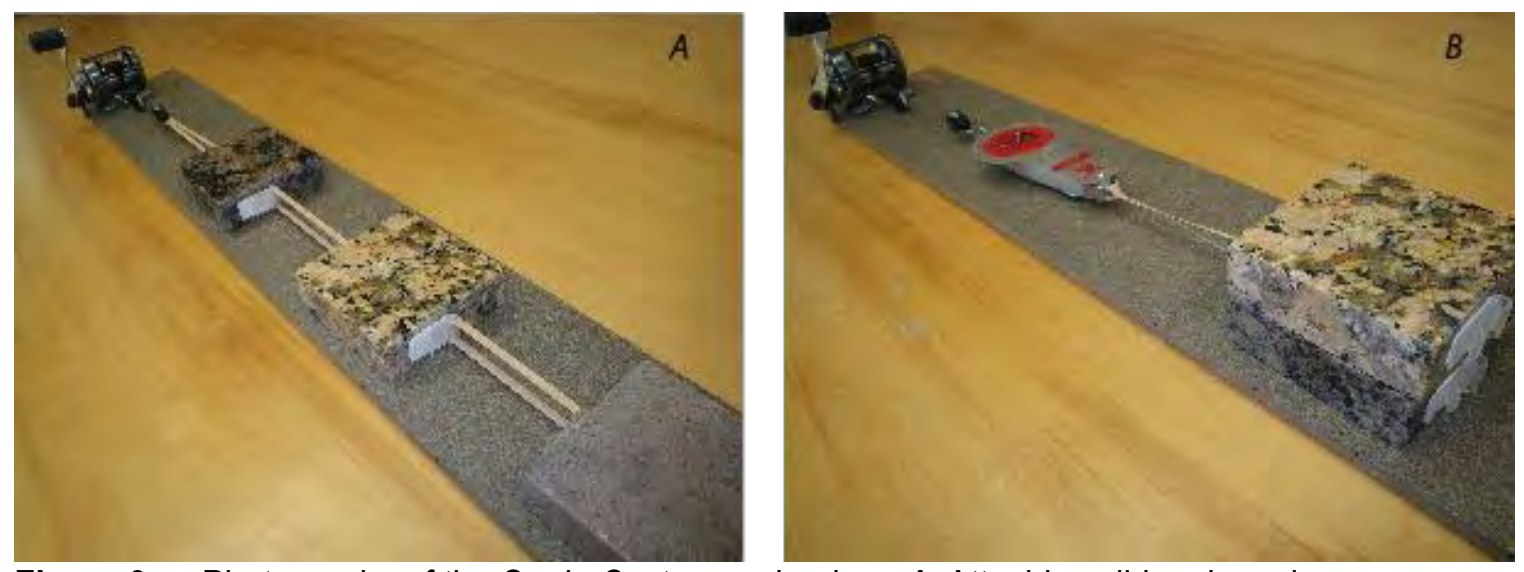

Figure 3. Photographs of the QuakeCaster mechanism. A, Attaching sliders in series demonstrates how earthquakes converse with each other through the transfer of stress, sometimes promoting earthquakes and sometimes inhibiting earthquakes. B, By inserting a small dial scale, students can measure the force buildup on a fault and look at failure stress and minimum stress. 


\section{Examples of QuakeCaster Experiments}

We ran experiments using QuakeCaster to test the four earthquake hypotheses. First, we performed three trials to measure both the time (in tenths of seconds) between events and to measure the slip distance (in centimeters). This required a minimum of three people. We placed a piece of white electrical tape along the entire length of the side of the nonskid-covered foam board. Then, one person reeled in the line at a constant rate (which simulates constant plate motion). One person used a Sharpie pen to mark the slip distance after each event (earthquake). Another person held the stopwatch and recorded the time of each event. After one trial, we measured the distance between events. We repeated this two more times. The three trial results are shown in figure 4.

For each trial, we calculated the root mean square (RMS) misfit value for each hypothesis (slip-predictable and time-predictable) to see how the QuakeCaster data compared to the hypotheses. (To calculate RMS misfit, we first subtracted the predicted slip distance from the observed slip distance for each data point. We squared each result, add all the results together, divided this total amount by the number of data points, and took the square root.) As shown in figure 1, Trial 1 suggests that earthquakes are best predicted by the time-predictable hypothesis. At first glance, the earthquakes in Trial 1 appear to fit the periodic hypothesis. However, the RMS misfit values suggest differently. The RMS misfit value for the slip-predictable hypothesis is 1.70 centimeters $(\mathrm{cm})$, but the RMS misfit value for the time-predictable hypothesis is $1.40 \mathrm{~cm}$. In contrast, Trial 2 suggests that earthquakes are best predicted by the slip-predictable hypothesis. The RMS misfit for the slip-predictable hypothesis is $1.86 \mathrm{~cm}$ and for the time-predictable hypothesis the RMS misfit value is $3.06 \mathrm{~cm}$. Trial 3 suggests, like Trial 1, that earthquakes are best predicted by the time-predictable hypothesis. The RMS misfit value for the slip-predictable hypothesis is $3.18 \mathrm{~cm}$ and for the time-predictable hypothesis the RMS misfit value is $2.45 \mathrm{~cm}$. Thus, none of the three trials perfectly matches the slippredictable, the time-predictable, or the periodic hypotheses. These tests show how difficult it is to accurately predict earthquakes: even when we grossly simplify the likely complexity and variability in the earth, we still do not get regular, predictable earthquakes. 


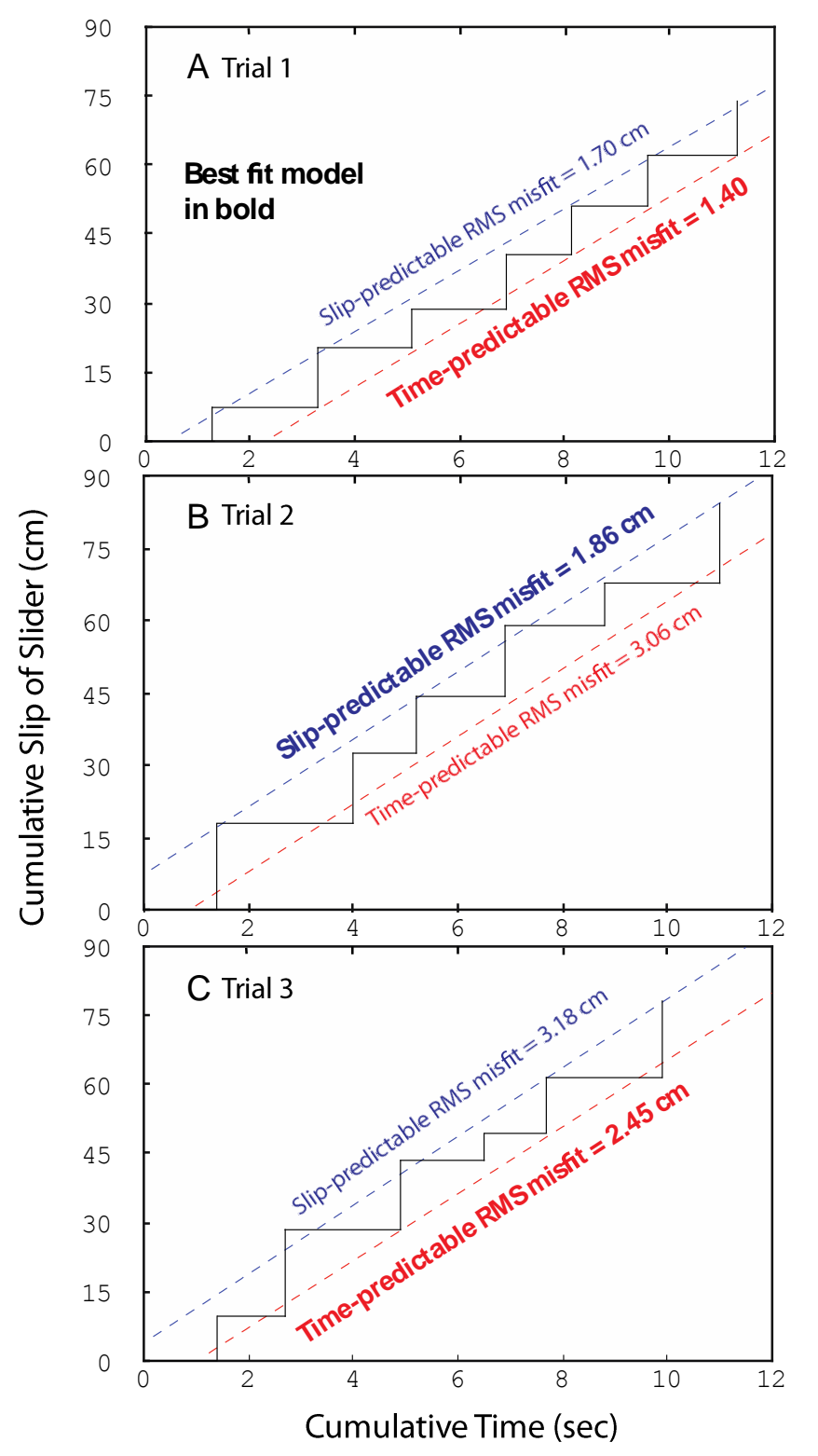

Figure 4. Graphs of test trials of the slip-predictable and time-predictable hypotheses. The hypothesis in bold indicates the better agreement with the observations in a given trial. We do not count the time to the first earthquake because the spring starts fully unloaded. A, Trial 1 data indicate that the time-predictable hypothesis is a better predictor of earthquakes than the slippredictable hypothesis. $B$, Trial 2 data indicate that the slip-predictable hypothesis is a more reliable predictor. $C$, Trial 3 data also fit the time-predictable hypothesis. The same slider and the same rubber band were used in each trial. The same person attempted to crank the reel at a constant speed in each trial, while another person marked the fault slip distance and one recorded the times. Any fault gouge (light dusting on the tile) we could see was brushed off after each trial. Then, we calculated the root mean square (RMS) misfit value to determine the best fit of the QuakeCaster data to a hypothesis. 
After the testing of the slip- and time-predictability hypotheses, we tested whether failure stress is an accurate predictor of earthquakes. We measured the force with the dial scale just before an earthquake occurred (failure stress) and measured the force just after an earthquake occurred (minimum stress). This required four people to ensure the most accurate data possible. One person turned the reel at a constant rate, one held the stopwatch and recorded the time of each event, one recorded the force just before an event, and one recorded the force immediately after an event. We performed three trials, and the results are shown in figure 5.

For each trial, we calculated the RMS misfit value for the slip- and timepredictable hypotheses to see how the QuakeCaster data compared to having a constant failure stress (equivalent to time-predictable) or to having a constant minimum stress (equivalent to slip-predictable). Figure 5 suggests that there is no identifiable failure stress; in all three trials, earthquakes did not occur at the same level of stress. Surprisingly, the trials indicate that the minimum stress is a better predictor of earthquakes than the failure stress. In Trial 1, the force-after RMS misfit value is 80 grams, whereas the force-before value is 210 grams. Again in Trial 2, the RMS misfit value is lower for the force after an earthquake. The RMS misfit value is 55 grams and the force-before value is 198 grams. In Trial 3, the force-after RMS misfit value is 76 grams and the force-before value is 110 grams. However, none of these trials perfectly fit either failure stress hypothesis. It is also surprising that the size of the shocks, as well as the failure and minimum stress, decreased markedly from Trial 1 to Trial 3. We have no good explanation for this, with the possible exception of minute quantities of naturally occurring fault gouge (granite dust) that one can see form on the sliding surface asperities (local high spots), which may reduce frictional properties.

The results of Trial 1 (from fig. $5 \mathrm{~A}$ ) are shown in figure 6A, together laboratory data for Westerly granite (Lockner and others, 2011) that give comparable results (fig. $6 B)$. 


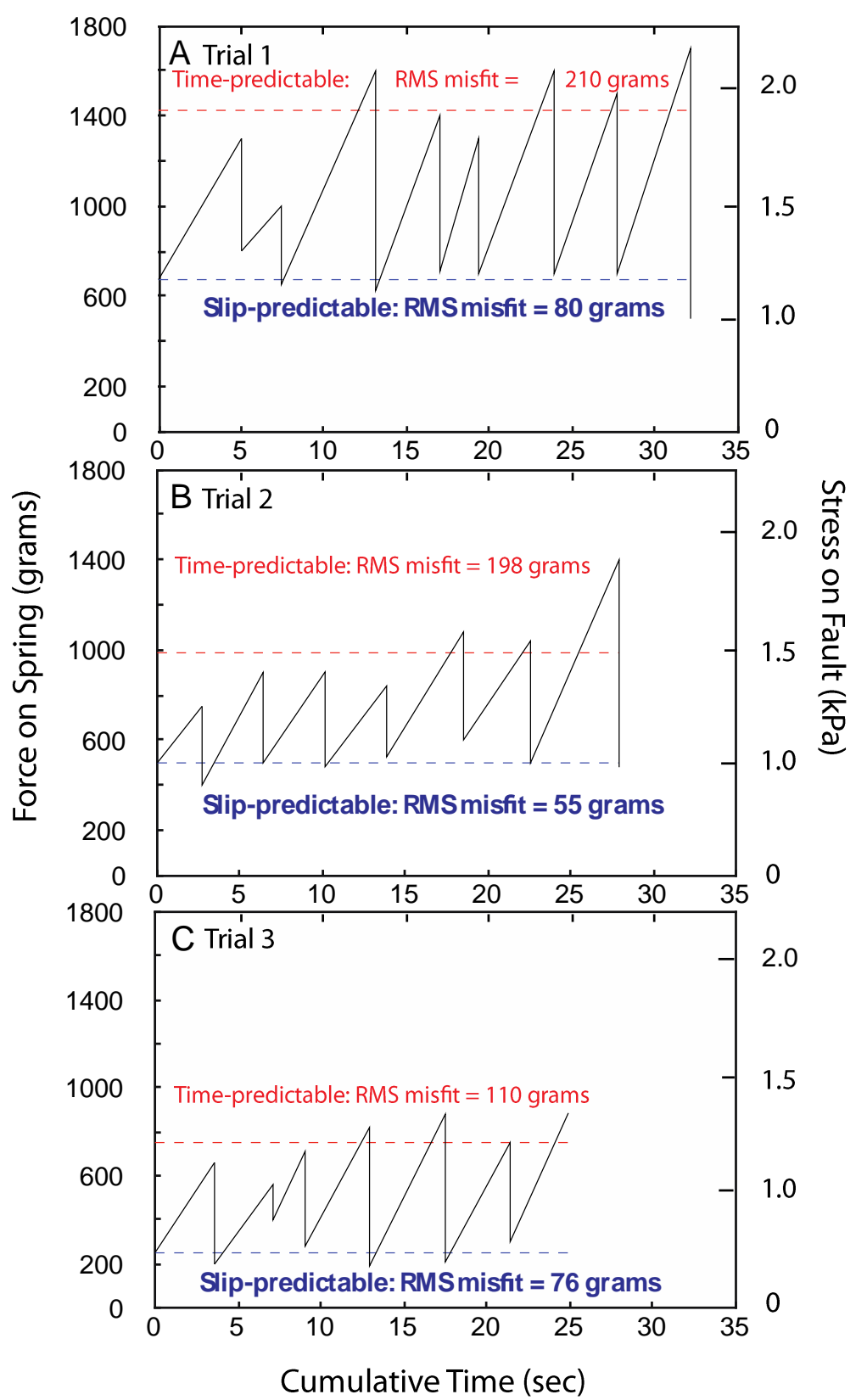

Figure 5. Graphs of test trials of constant minimum and constant failure stress. The hypothesis in bold indicates the better agreement with the observations in a given trial. $A$, Trial 1 data suggest that minimum stress is a better earthquake predictor than failure stress. $B$, Trial 2 data also suggest that minimum stress is a better predictor. $C$, In contrast, Trial 3 data suggest that failure stress is a more reliable predictor of earthquakes. The same slider and the same rubber band were used in each trial. The same person attempted to crank the reel at a constant speed in each trial, while one person recorded the force on the spring (grams) before an event, one recorded the force on the spring (grams) after, and one recorded the time. Then, we calculated the root mean square (RMS) misfit value to determine the best fit of the QuakeCaster data to a hypothesis. 

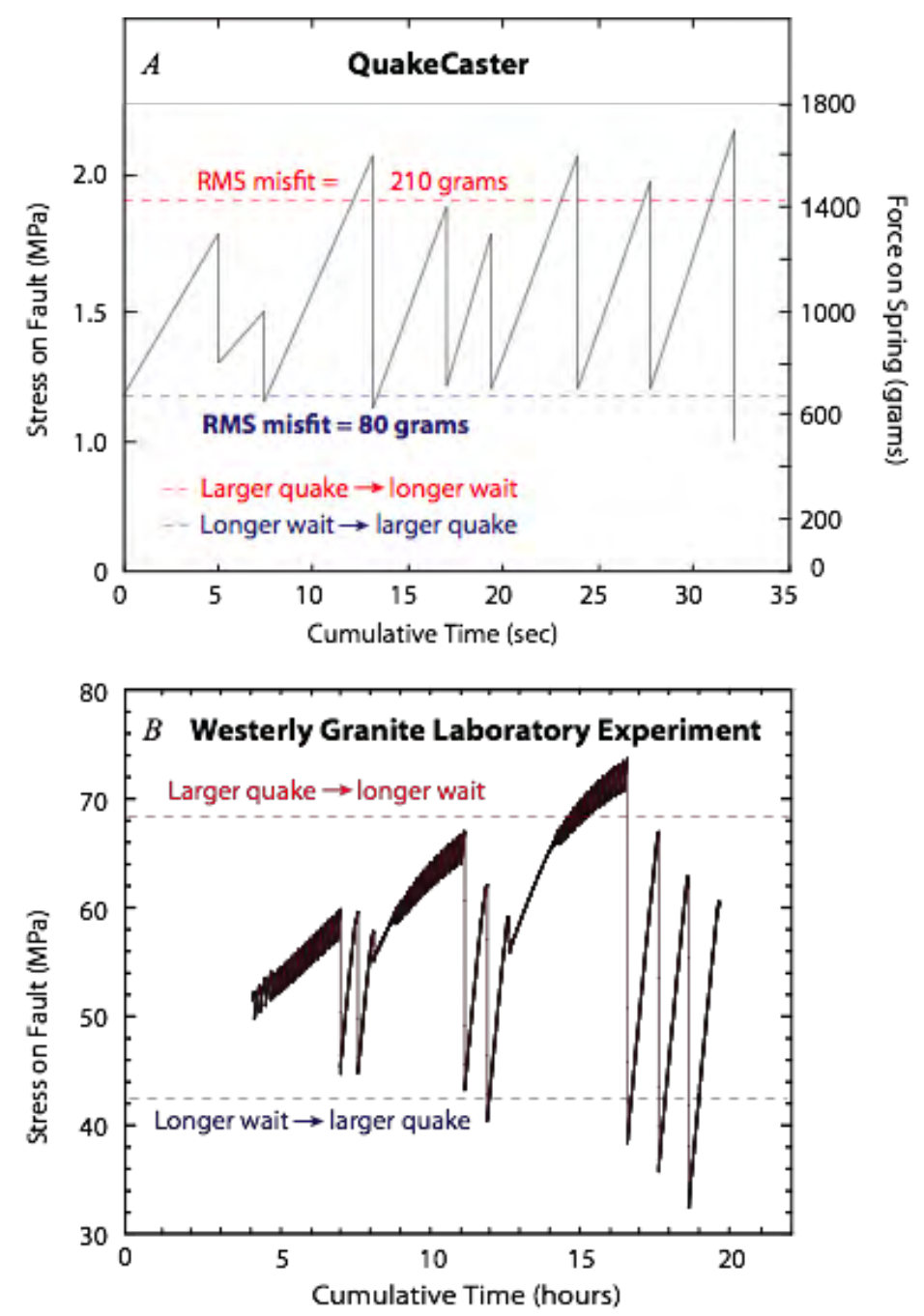

Figure 6. Graphs comparing QuakeCaster and a laboratory experiment on failure stress. A, QuakeCaster suggests that minimum stress might be a better earthquake predictor than failure stress. B, A 3-inch-diameter cylinder of Westerly granite with a 30-degree saw-cut and 600-grit abrasive lapping of fault surfaces, sheared under constant confining pressure of 50 megapascal (MPa) and a constant loading rate of 0.1 micron/second (Lockner and others, 2011). Here, neither a constant failure stress nor a minimum stress forecasts future laboratory earthquakes. For stress conversion, 1,000 kilopascal $(\mathrm{kPa})=1 \mathrm{MPa}=10$ bar.

\section{QuakeCaster Relates to the Parkfield Section of the San Andreas Fault}

The Parkfield section of the San Andreas Fault is the best documented and the most periodic earthquake sequence known on the planet, but its event sequence is neither time- nor slip-predictable. The Parkfield fault section data, at first glance, appear to be roughly periodic, with magnitude 6 earthquakes roughly every 20-30 years. Christopher Scholz (2002) assessed Parkfield data from an earlier time period, 1850-1988. However, 
Scholz points out that the 1934 Parkfield earthquake occurred roughly a decade earlier than the average interval, and since his work, we now know that the 2004 Parkfield earthquake struck about 1-2 decades late (fig. 7B). This data emphasizes the fact that even the most predictable earthquakes deviate from slip- or time- dependent hypotheses. Also, Murray and Segall (2002) found that the Parkfield magnitude 6 earthquake is not time-predictable. Based on the 1850-1966 inter-event times, the most recent earthquake after 1966 should have occurred sometime between 1973 and 1987, but it did not strike until 2004, about 1-2 decades late, and it was also somewhat larger than its recent predecessors. This record emphasizes that even the most predictable earthquakes deviate from slip- or time- dependent hypotheses. If these hypotheses do not fit a simple, seemingly periodic fault, then how can they apply to a larger and more complex fault?

Even though the magnitude $(M) \sim 6$ Parkfield shocks are not periodic, time-, or slip-predictable, there is a class of very small $(M=1-3)$ shocks, known as repeaters, whose seismic waveforms are nearly identical, and so are thought to occur at the same location and have the same size and slip. Rubinstein and others (2012a and 2012b) show the time history for Parkfield repeating earthquake sequence \#1 (fig. 7C). At first glance, this set of $M \sim 2$ repeaters appears periodic, and is certainly more periodic than the QuakeCaster shocks in figure $3 A$ and the $M \sim 6$ shocks in figure $3 B$. But upon closer inspection, the repeaters are not periodic, nor are they time- or slip-predictable, as demonstrated by Rubinstein and others (2012a and 2012b).

The QuakeCaster stacked-slider earthquakes are $M \sim-4.5$. This means that the scale difference between the $M \sim 6$ and the repeating $M \sim 2$ events at Parkfield is about the same as the difference between the repeaters and QuakeCaster events. To estimate the QuakeCaster magnitude we calculated the seismic moment of a typical event from the slip $(\sim 10 \mathrm{~cm})$, slider area $\left(\sim 100\right.$ square centimeters, $\left.\mathrm{cm}^{2}\right)$, and the rubber band crosssection $\left(\sim 0.1 \mathrm{~cm}^{2}\right)$, Poisson's ratio $(\sim 0.25)$ and length change of the rubber band in response to a fixed tension to calculate its Young's modulus $\left(\sim 6 \times 10^{6}\right.$ dyne- $\left.\mathrm{cm}^{-2}\right)$. We converted Young's modulus to the shear modulus, arriving at the seismic moment $\left(\sim 3 \times 10^{9}\right.$ dyne-cm), which was then converted to magnitude.

Students can easily perform these calculations by measuring the change in length of the rubber band for a given force on the dial scale. Young's modulus, $E$, is the tensile stress/tensile strain, which equals the force on the rubber band $(F)$ multiplied by the original length of the rubber band $\left(L_{\mathrm{o})}\right.$ divided by the original cross section of the rubber band $\left(A_{\mathrm{o})}\right.$ multiplied by the length change $(\Delta L)$; the full equation is $F L_{\mathrm{o}} / A_{\mathrm{o}} \Delta L$. Young's modulus can be converted to the shear modulus $G$, by $G=E / 2(1+v)$, with Poisson's ratio $v$ about 0.25 . The seismic moment $\left(M_{\mathrm{o}}\right)$ is calculated by multiplying the slip (u), by the area of the fault $(A)$, by the shear modulus $(G)$. Then the magnitude equals $2 / 3\left(\log M_{\mathrm{o}}\right.$ 16.1).

A comparison of QuakeCaster Trial 1 (from fig. 4A), Parkfield $M \sim 6$ shocks, and Parkfield $M \sim 2$ repeaters is shown in figure 7. 

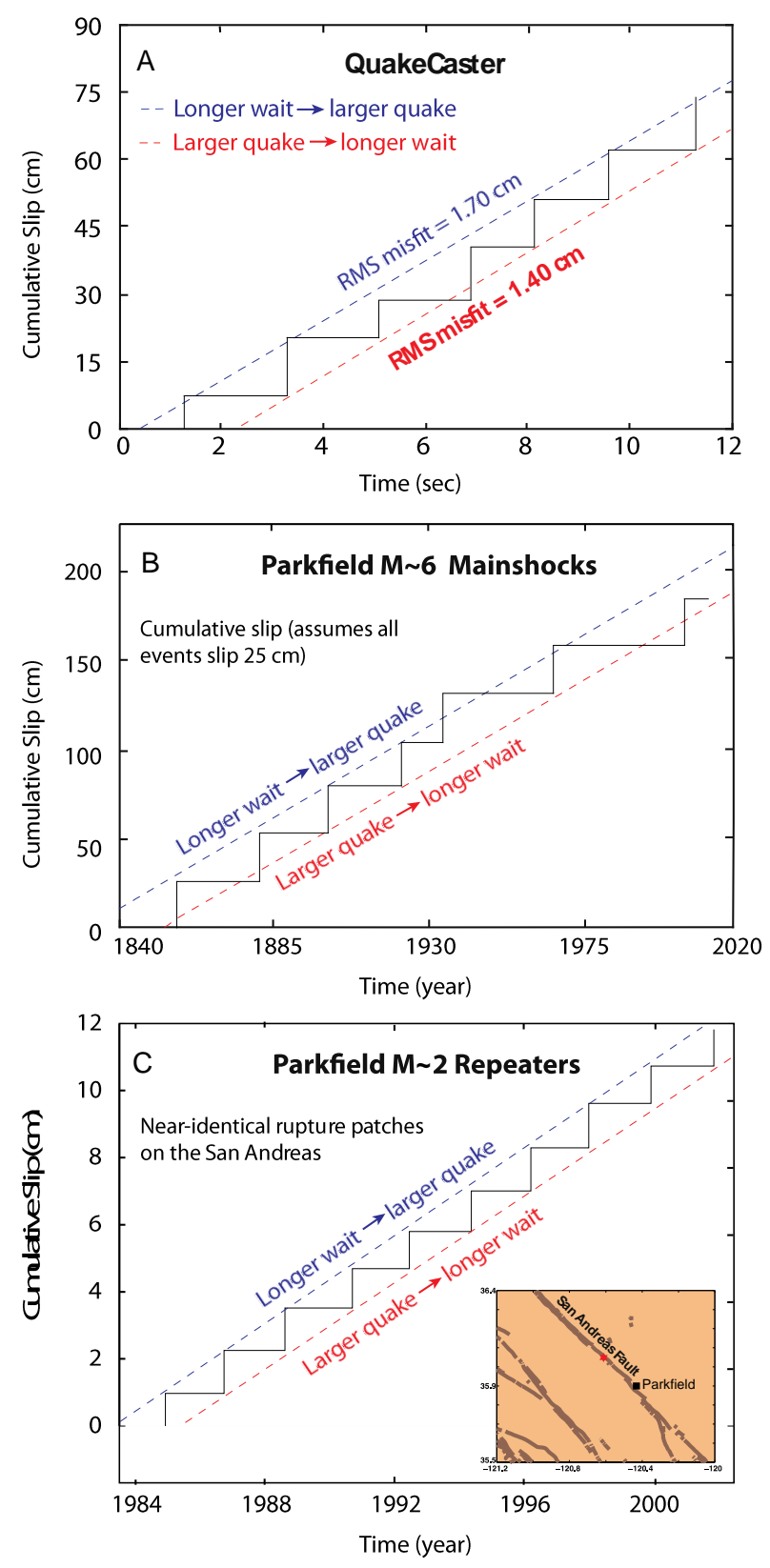

Figure 7. Graphs of time and slip predictability in QuakeCaster and at Parkfield, California. A, For QuakeCaster, the hypothesis in bold indicates better agreement with the observations for this trial. $B$, The magnitude $(M) \sim 6$ shocks are neither time- or slip-predictable. $C$, The Parkfield, California, repeating $M \sim 2$ earthquakes, known as repeaters, appear to be more periodic. Estimated best-fit lines (blue and red) are drawn in to see how the data compares to slip- and time-predictable hypotheses. The $M \sim 6$ data is from Bakun and McEvilly (1984) and Murray and Langbein (2006). Notice that the slip of QuakeCaster earthquakes is closer to the repeater slip than the repeaters are to the $M \sim 6$ shocks. Inset map of Parkfield shows location of the San Andreas Fault in the vicinity of Parkfield, California. The red dot is the San Andreas Fault Observatory at Depth drill site. RMS, root mean square; cm, centimeters. 


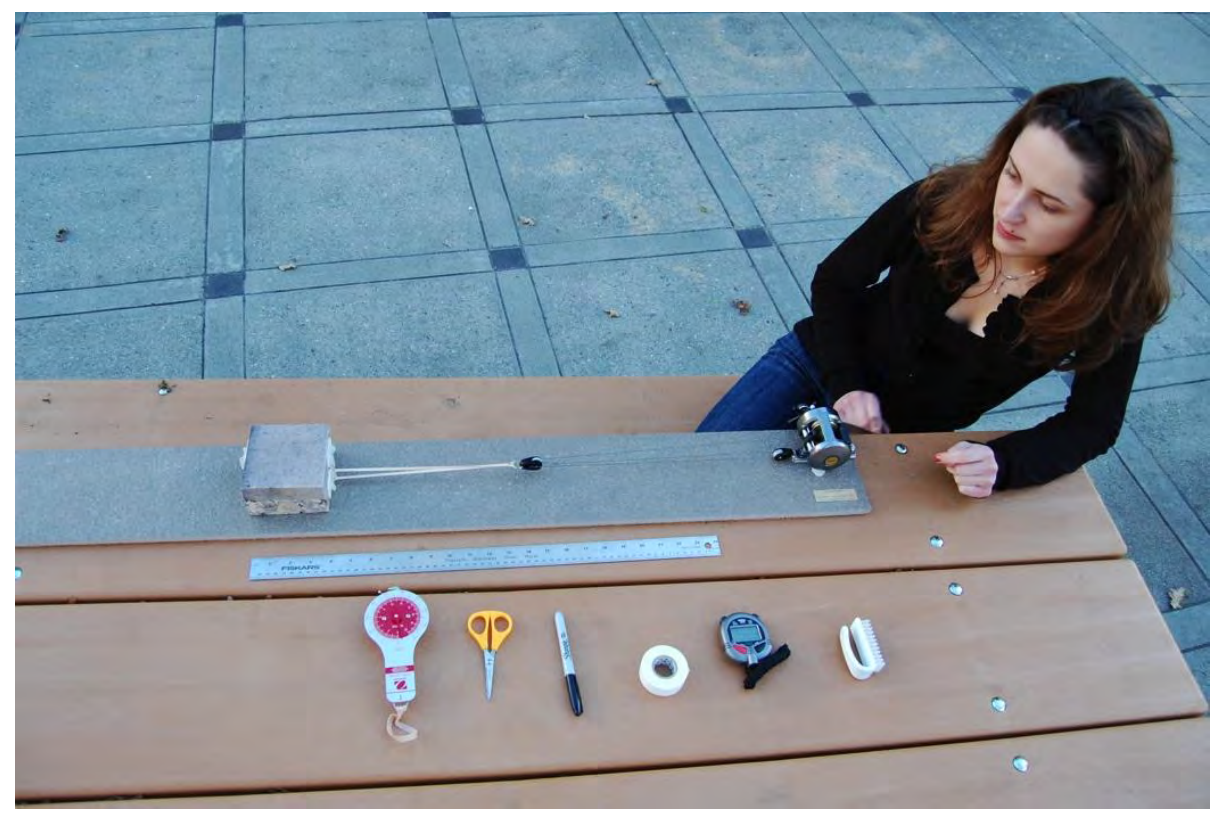

Figure 8. Photograph of a student using the QuakeCaster mechanism. A student turns the fishing reel at a constant rate, which simulates constant tectonic-plate motion, to observe the behavior of a large earthquake, represented by two stacked granite sliders. The granite slider is in frictional contact with the nonskid-covered foam board, which represents friction in a fault. The rubber band that joins the slider and the fishing reel simulates the Earth's elastic crust. In one experiment, students test expectations for the behavior of large and small earthquakes. Students can observe the earthquake behavior of two sliders compared to the earthquake behavior of just one slider.

\section{Measuring the Fault Friction in QuakeCaster}

After running QuakeCaster just once, a light dusting, which represents fault gouge, is visible on the nonskid-covered foam board. Fault gouge forms along real faults as a result of friction between fault faces when they slide past each other, grinding rocks into a pulverized powder. After assessing rock samples, Moore and Rymer (2007) found saponite and talc, in fault gouge within the San Andreas Fault at the SAFOD (San Andreas Fault Observatory at Depth) drill site. These minerals decrease friction within faults and could therefore be responsible for fault creep at shallower (saponite) and greater (talc) depths along the San Andreas (Moore and Rymer, 2007). Byerlee (1978) also determined that gouge decreases friction. He explains the adhesion theory of friction, which states that surfaces touch at asperities and a great amount of shear stress is needed to overcome their contact.

Rock materials, when dry, have a coefficient of friction of about 0.65 . For wet samples and for samples with fault gouge, the coefficient of friction can be much lower, perhaps as low as 0.2. Using QuakeCaster, students can calculate the coefficient of friction one of two ways. One option is to divide the force before an event by the weight of the slider. Another option is to slowly tilt the nonskid-covered foam board until the sliders begin to move down the slanted tile, and then measure the angle between the table 
and the tile. The tangent of this angle is the coefficient of friction. Our tests have shown a friction of coefficient of about 0.5 . However, the coefficient of friction can change during the experiment. For example, if fault gouge accumulates over multiple trials, the coefficient of friction will most likely decrease. After running additional trials, we found evidence of decreased friction due to observed fault gouge. As figure 5 shows, the amount of force necessary to overcome friction decreased over multiple trials.

\section{Measuring the Elasticity of Earth's Crust in QuakeCaster}

To determine if the elasticity of the rubber band behaved linearly over the range of forces it was subjected to in QuakeCaster experiments, we calculated the rubber band's stiffness. We did this by attaching a fishing scale to the rubber band, and then hanging weight from the scale. Then we measured how far the rubber band had stretched. If two times the weight is added to the rubber band, the rubber band should also double in length. The elasticity can be determined by dividing the increment in force by the increment in length change.

\section{Audience Participation in QuakeCaster Experiments}

Because the audience becomes involved in the earthquake prediction process during experiments, it is easy for them to see why it is so difficult to predict earthquakes. When teaching with QuakeCaster, members of the audience will be asked to predict events based on force and time (figs. 8, 9, 10). For example, audience members will observe the time between events and then will state whether or not they believe the same amount of time passed between these events. Observations are crucial to their understanding of earthquake behavior. Then, audience members will time the actual amount of time between events, which will either confirm or negate their observations. We have used QuakeCaster with college students, middle-school students, and the general public. People have been quite vocal and eager to share their observations and predictions. In some instances, however, audience members have hesitated to share their thoughts for fear of being wrong. The beauty of QuakeCaster, though, is that there is no wrong answer! Observations are part of the prediction process in laboratory and real-life settings.
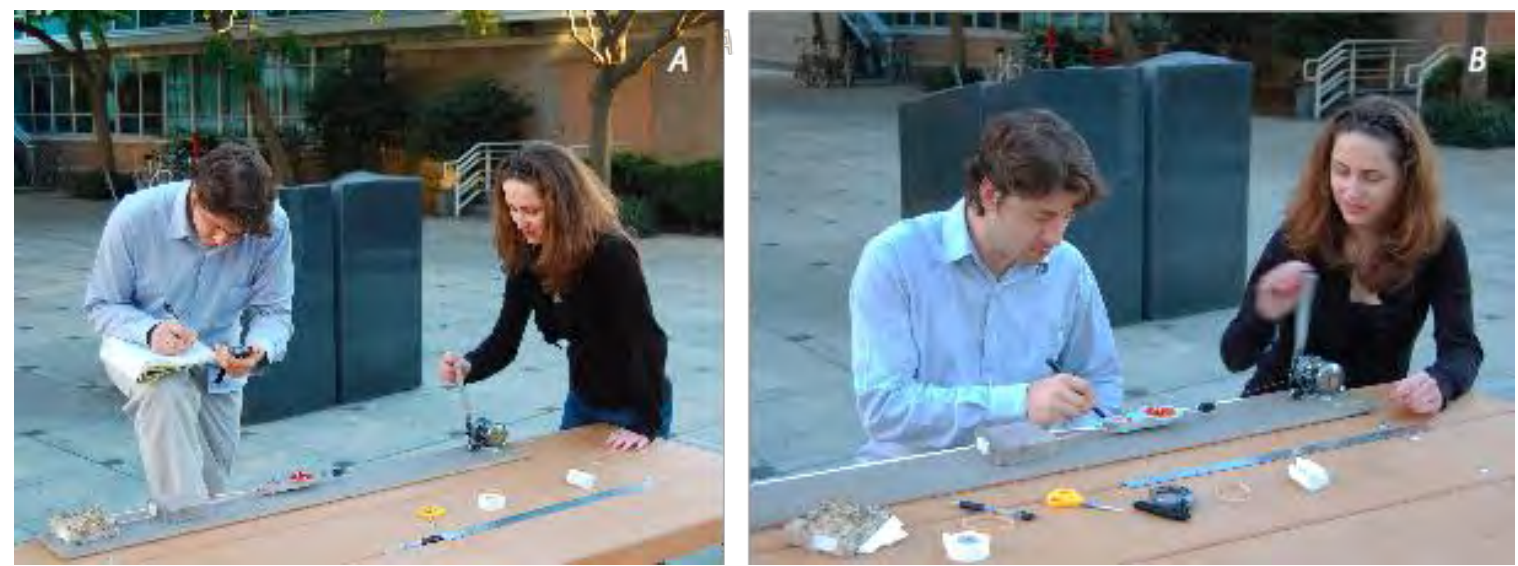

Figure 9. Photographs of students using the QuakeCaster mechanism. $A$, One student uses a dial scale to record the force before an event and the force immediately after an event, while a 
second student turns the fishing reel. In this trial, the first student is also timing when each event occurs. However, it is easier to have a third person hold the lap timer, because it becomes difficult for one person to record the force and time. This experiment allows students to see if minimum stress or failure stress is a reliable predictor of earthquakes, as shown in figures 2 and 4 . $B$, One student marks the rupture length for each event while a second student turns the fishing reel. $A$ piece of white electrical tape was placed along the edge of the nonskid-covered foam board. The first student marks the slider's front edge after each event. After marking rupture lengths, students use a ruler to measure the distance between events. That data can be plotted and graphed, as shown in figures 1 and 3.

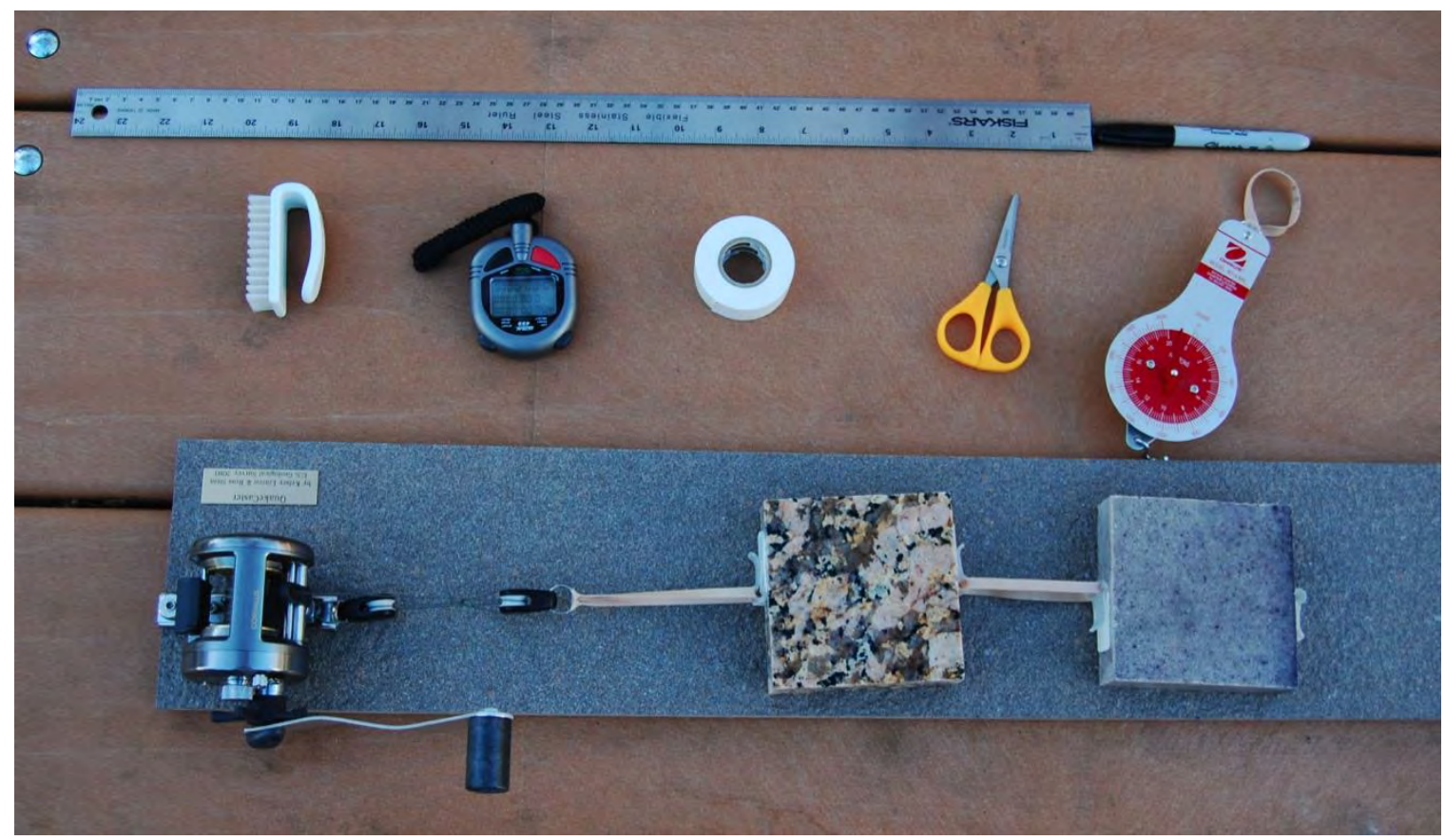

Figure 10. Photographs of the QuakeCaster mechanism. By attaching a rubber band between two sliders, students can see how earthquakes "converse" with one another through the transfer of stress along a fault. One student can turn the fishing reel, while the other students can observe and record the sliders' interactions.

\section{Conclusion}

We have found that QuakeCaster speaks to middle school students, graduate students, the public, insurance executives, and research seismologists. The QuakeCaster model illuminates Earth processes and encourages experimentation while making learning fun. People have been vocal and eager to share their observations, traits that are crucial to scientific inquiry and discovery. By involving audience members in experiments, QuakeCaster makes it easy to see why it is so difficult to predict earthquakes.

The results of QuakeCaster suggest that time- and slip-predictable hypotheses are not always reliable predictors of earthquakes. By carrying out QuakeCaster experiments, 
students can understand the difficulty scientists have in predicting earthquakes. The Earth's behavior is not uniform, and earthquake occurrences don't always follow patterns. While we have only run a few tests using QuakeCaster, the model demonstrates how challenging it is to warn the public of the likelihood of an earthquake in a specific time period.

\section{Acknowledgments}

We thank Volkan Sevilgen, Jacob DeAngelo, Brian Kilgore, and Benjamin Hankin, and Patty McCrory for advice, innovations, and assistance while we designed, prototyped, and tested QuakeCaster. We thank David Lockner, Diane Moore, and Menlo Middle School science teacher Tammy Cook for perceptive reviews. We are also grateful to Jacob for coming up with its name! We also thank Max Willis for revisions to the appendixes in version 1.1.

\section{References Cited}

Bakun, W.H., and McEvilly, T.V., 1984, Recurrence models and Parkfield, California earthquakes: Journal of Geophysical Research, 89, p. 3051-3058.

Bufe, C.G., Harsh, P.W., and Burford, R.O., 1977, Steady-state seismic slip-A precise recurrence model: Geophysical Research Letters, 4, p. 91-94, doi:10.1029/GL004i002p00091.

Byerlee, J., 1978, Friction of rocks: Pure and Applied Geophysics, v. 116, p. 615-626.

Campbell, K.W., 1982, Bayesian analysis of extreme earthquake occurrences-Part I, Probabilistic hazard model: Bulletin of the Seismological Society of America, v. 72, 5, p. $1689-705$.

Lockner, D.A., Morrow, D., Moore, D., and Hickman, S.H., 2011, Low strength of deep San Andreas fault gouge from SAFOD core: Nature, v. 472, p. 82-85.

Moore, Diane E., and Rymer, Michael J., 2007, Talc-bearing serpentinite and the creeping section of the San Andreas fault: Nature, v. 448, p. 795-797.

Murray, J. and J. Langbein, 2006, Slip on the San Andreas Fault at Parkfield, California, over two earthquake cycles, and the implications for seismic hazards: Bulletin of the Seismological Society of America, v. 96, S283-S303, doi: 10.1785/0120050820.

Murray, J., and Segall, P., 2002, Testing time-predictable earthquake recurrence by direct measure of strain accumulation and release: Nature, v. 419, p. 287-291, doi:10.1038/nautre00984.

Reid, H.F., 1910, The mechanics of the earthquake, in Lawson, A.C., ed., The California Earthquake of April 18, 1906: Report of the State Earthquake Investigation Commission, v. 2, p. 192.

Rubinstein, J.L., Ellsworth, W.L., Beeler, N., Kilgore, B.D., Lockner, D., and Savage, H., 2012b) Fixed recurrence and slip models better predict earthquake behavior than the time- and slip-predictable models 2 - Laboratory earthquakes: Journal of Geophysical Research, Solid Earth, v. 117, no. B2, doi: 10.1029/2011JB008723.

Rubinstein, J.L., Ellsworth, W.L., Chen, K.H., and Uchida, N., 2012a, Fixed recurrence and slip models better predict earthquake behavior than the time- and slip-predictable models 1-Repeating earthquakes: Journal of Geophysical Research, Solid Earth, v. 117, no. B2, doi: 10.1029/2011JB008724. 
Scholz, C.H., 2002, The mechanics of earthquakes and faulting (2d. ed.): Cambridge University Press, Cambridge, 473.

Schwartz, D.P., and Coppersmith, K.J., 1984, Fault behavior and characteristic earthquakes: examples from the Wasatch and San Andreas fault zones: Journal of Geophysical Research, 89, 5681-5698, doi:10.1029/JB089iB07p05681.

Shimazaki, K., and Nakata, T., 1980, Time-predictable recurrence model for large earthquakes: Geophysical Research Letters, 7, p. 279-282.

Stein, R.S., 2003, Earthquake conversations: Scientific American, v. 288, 1, p. 72-79. 


\section{Glossary}

Aftershock-Earthquakes that follow a mainshock and have the attribute that their frequency decreases roughly inversely proportional to time (referred to as Omori's law). Aftershocks may occur on the slipped fault or far from it.

Asperities-Rough, uneven surfaces in frictional contact along a fault. Asperities can be thought of as the stuck patches of a fault.

Cascading Shocks - One earthquake transfers its stress further down a fault and promotes more earthquakes. See stress triggering.

Clamping Stress - (Also termed "normal" stress.) A force that acts perpendicular to a plane. This element of stress compresses the plane.

Coefficient of Friction-The influence of unclamping stress relative to shear stress in triggering an earthquake. It is generally held to range between 0.0 and 0.8 . Using QuakeCaster, there are two ways to calculate the coefficient of friction. One option is to divide the force just before an event by the weight of the slider. Another option is to slowly tilt the nonskid-covered foam board until the sliders begin to move down the slanted tile, and then measure the angle between the table and the tile. The tangent of this angle is the coefficient of friction.

Coulomb Failure Criteria-When a fault is on the verge of slipping, either increasing the shear stress or decreasing the clamping ("normal") stress, will promote an earthquake. Earthquake Magnitude $(M)$-A measure of the amount of energy released by an earthquake; used to size earthquakes. The magnitude is proportional to the logarithm of the seismic moment. Strictly, the Richter magnitude is the deflection of a Wood-

Anderson seismometer needle, in $\mathrm{cm}$, for an earthquake 100 kilometers $(\mathrm{km})$ away.

Fault Creep-The slow continuous movement of fault faces as they slide past each other due to constant stress acting along the fault.

Fault Friction-The force which must be overcome for the slippage of fault surfaces.

Fault Gouge - A pulverized powder that forms along faults as a result of friction between fault faces when they slide past each other and grind down rocks. As gouge accumulates, fault friction decreases.

Fault System-Two or more adjoining faults.

(Fixed) Failure Stress - When a certain amount of stress accumulates along a fault, an earthquake will occur.

Force-An influence that causes an object to change its motion.

Foreshock - A small earthquake that sometimes precedes a larger earthquake by any amount of time (seconds, days, weeks) and occurs near larger earthquake. Invariably, the term 'foreshock' is used retrospectively; there are no known attributes of foreshocks that distinguishes them from other shocks.

Friction-The opposing force encountered when one object moves relative to another object, to which it is in contact.

$\mathbf{k P a}$ Unit-Kilopascal; a unit of measure of stress $(1 \mathrm{kPa}=1,000$ pascals $=10 \mathrm{bar})$.

Load - A small force or a small amount of tension.

Loading Rate-In this experiment, loading rate is how quickly force builds up. Stress is the force divided by the surface area. In QuakeCaster, when the force builds up to 1,000 grams, one $10 \times 10 \mathrm{~cm}$ slider has a shear stress of roughly $0.96 \mathrm{kPa}$. With the QuakeCaster model, because the surface area is constant, we can look at force alone. 
(Fixed) Minimum Stress - After an earthquake, the amount of stress along a fault decreases to this amount.

North Anatolian Fault-A continental transform fault located in Turkey that experienced the most spectacular "falling-domino" sequence of large earthquakes ever recorded-12 earthquakes ruptured along this fault since the 1939 Erzincan magnitude $(M)=7.9$ earthquake through the $1999 M=7.4$ and $M=7.1$ Izmit-Düzce shocks. This sequence has been used to argue for earthquake interaction by stress triggering — one earthquake transfers its stress farther down a fault and causes another earthquake.

Parallel Fault System - Two or more parallel faults. Examples include the San Andreas and Hayward Faults in northern California, or the San Andreas and San Jacinto Faults in southern California.

Periodic Hypothesis - This earthquake prediction hypothesis states that the same amount of fault slip is separated by the same amount of time. There is some evidence for this, particularly in the study of the data of very small earthquakes on creeping faults.

Poisson Hypothesis - This earthquake prediction hypothesis states that earthquakes occur randomly in time and have randomly varying size. This hypothesis is widely used, particularly when little information about a fault and its past earthquakes is available.

Root mean square (RMS) Misfit Value - It is the square root of the means of the squares of the values. Used in statistics, it reveals how well data fit hypotheses. To calculate the RMS misfit, subtract the predicted value from the observed value, square each result, add all the results together, divide this total amount by the number of data points, and take the square root.

Seismic Moment $\left(M_{0}\right)$-A measure of an earthquake's size. With QuakeCaster, the moment is the fault contact area (here a $10 \times 10 \mathrm{~cm}$ slider surface), multiplied by the elastic stiffness (the stiffness of the rubber band), multiplied by the amount of slip (measured in $\mathrm{cm}$ ).

Shear-A deformation that occurs as a result of stress causing two fault faces to slide parallel to each other.

Shear Stress-A force that acts parallel to a fault plane. This element of stress causes slippage along the plane.

Slip-predictable Hypothesis-This earthquake prediction hypothesis states that the longer the time stress accumulates, the greater the amount of fault slip in the next earthquake. Another way of framing this hypothesis is that earthquakes drop the amount of stress along a fault to a fixed minimum or to a background amount.

Stress-The force acting on an object divided by the surface area.

Stress Buildup-The stress that accumulates within a fault due to friction between fault faces. When the stress acting on the fault overcomes the frictional resistance, the fault will slip.

Stress Shadow - When earthquakes have been inhibited because the Coulomb stress acting on faults has decreased. Stress shadows can be caused by decreasing shear stress or by increasing clamping ("normal") stress. One earthquake can cause a stress shadow farther down a fault, thus minimizing the likelihood of another earthquake.

Stress Triggering - When one earthquake transfers its stress farther down a fault and causes another earthquake. Stress can be transferred by increasing shear stress or by decreasing clamping ("normal") stress. 
Tectonic Plates - Giant slabs of lithosphere, part of the Earth's crust. There are eight primary plates, which are made of continental and oceanic rocks and minerals. These materials cause the plates to slide, float, and interact over the asthenosphere. The plates' interactions are responsible for earthquakes and for the Earth's surface features.

Time-predictable Hypothesis - This earthquake prediction hypothesis states that the larger the amount of fault slip in the last earthquake, the longer the time until the next earthquake. Another way of framing this hypothesis is that earthquakes occur when a failure threshold stress is reached.

Toggling Shocks-One earthquake can either inhibit or promote another earthquake. 


\section{Appendix 1. How to Build QuakeCaster and Parts Buying Guide}

\section{Parts and Equipment}

- 3 granite sliders

- 48×6-inch plastic board (foamed PVC $1 / 8$ inch thick)

- Sandpaper

- 4-6 photo clips

- Ruler

- Masking tape

- 3M 4200 Marine Adhesive Sealant

- Corvalus 300 fishing reel

- Custom handle to replace Corvalus handle (optional)

- Drill, screws

- Ronstan Series 19 Slide with Jib Sheet Fairlead and Spring-Loaded Track Stop, and C-Track Traveler System

- 2 small pieces of rubber

- 4 pulleys ("kite-surfer blocks")

- Thin metal wire

- Cork

- X-Acto knife

- Spray-on adhesive

- Size 64 rubber bands

- Force (stress gauge)

- Stopwatch

- Small brush

- White electrical tape

- Marker

- Pelican case

- Extra foam for Pelican case

- Karabiner

\section{Step 1}

- Gather materials.

- Obtain at least 2 granite sliders. Each should be approximately $4 \times 4$ inches and around $1 \frac{1 / 4}{4}$ inch thick.

\section{Step 2}

- Cut the foamed PVC plastic board to desired length at a plastic store. Recommended size is $48 \times 6$ inches.

- Using the spray adhesive, adhere sandpaper to one side of the plastic board. It is best to glue the sandpaper backing directly to the board so that the sandpaper can 
be removed and replaced easily. Remove sandpaper from one side about 4 to 5 inches so that the transfer paper is revealed.

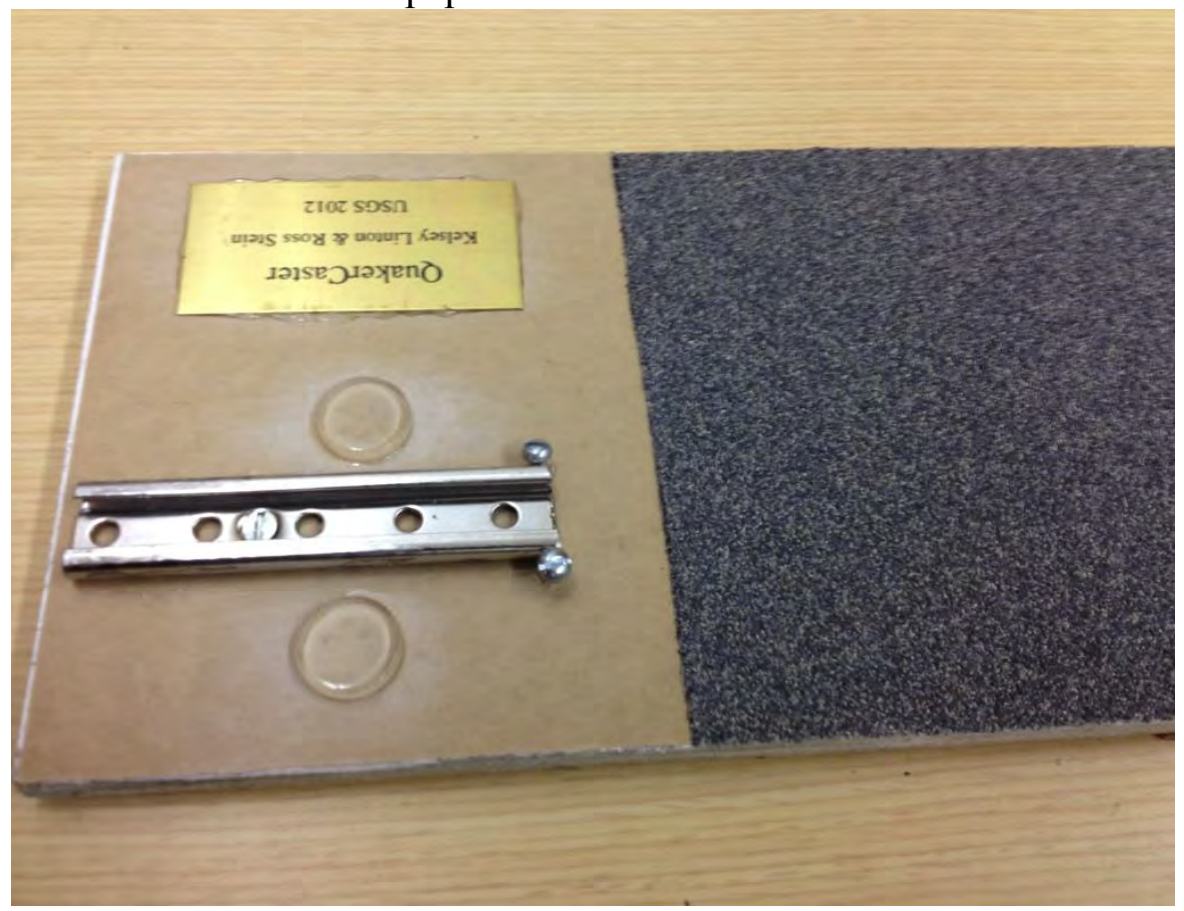

Photograph of sandpaper with transfer paper glued to the plastic board.

\section{Step 3}

- Prepare the sliders for use:

- Using sandpaper, roughen the backs of 2 photo clips.

- Using a ruler, mark the center of one side of a slider. Also mark the center of the opposite side.

- Use a big dollop of 3M 4200 Marine Adhesive Sealant on the back of one photo clip. Attach it to the center of one slider's side. Let dry. Repeat for second photo clip and opposite side.

- Repeat previous step for second slider.

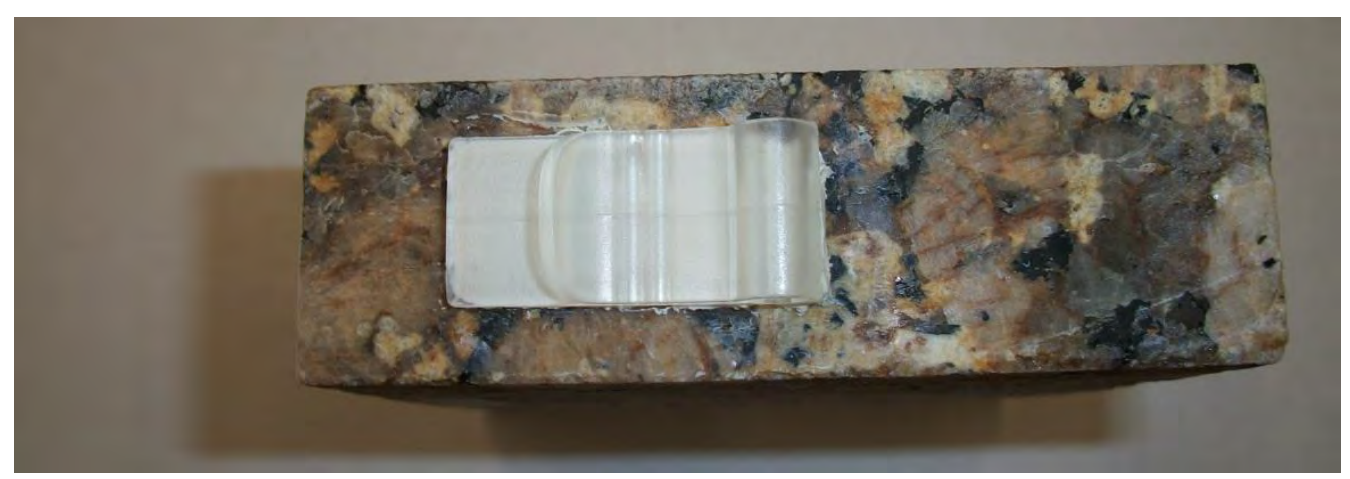

Photograph of photo clip attached to granite slider. 
- The rough side of the slider should be sandblasted to increase the friction with the sandpaper. Conventional sanding gives too uniform of a finish compared to the rough nature of a sandblast.

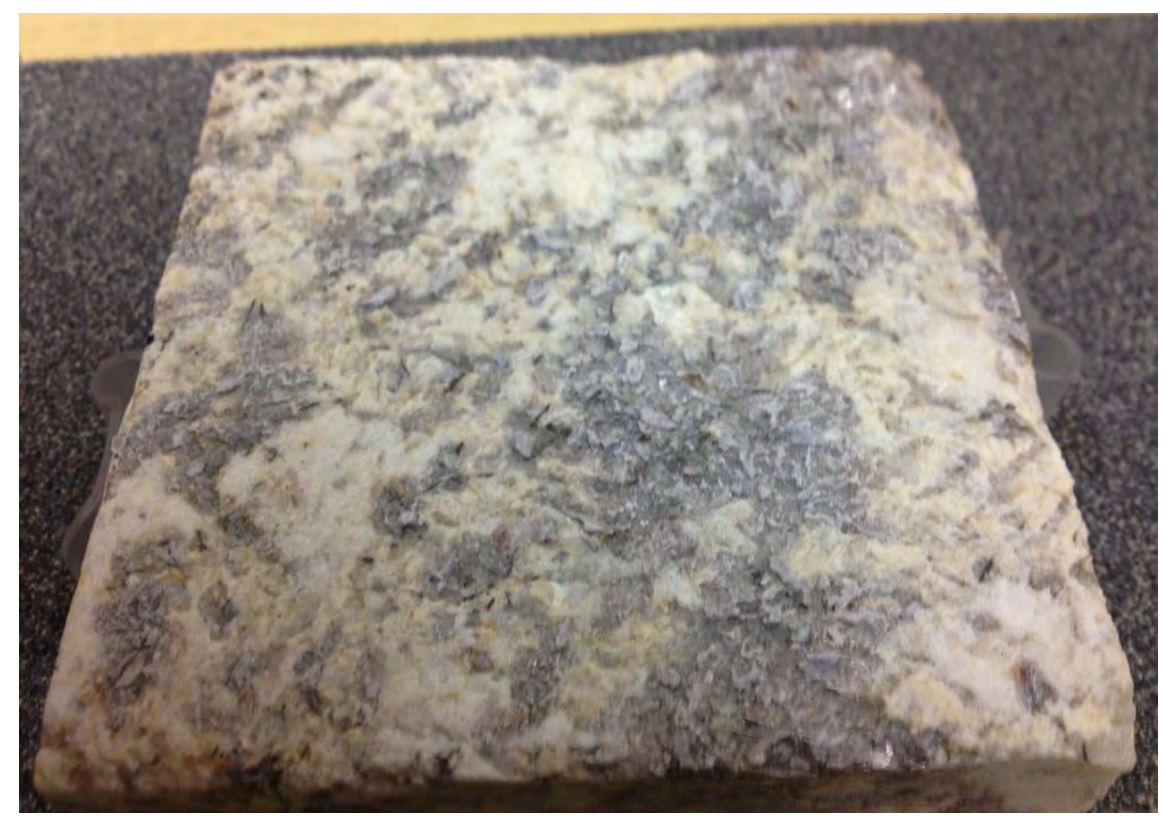

Photograph of sandblasted side of the slider showing the rough asperities.

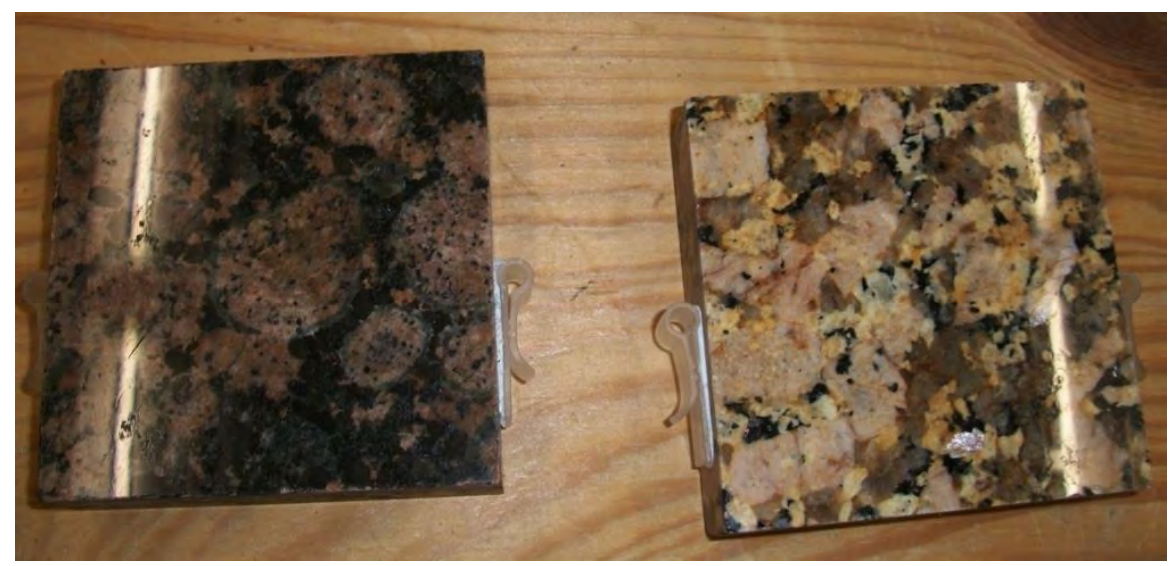

Photograph of granite sliders. Each slider is $4 \times 4$ inches.

\section{Step 4}

- Prepare the fishing reel for use as a crank:

- Optional: Remove the handle of the Corvalus 300 reel. Replace with a longer handle. This will lessen the weight you feel when turning the handle during the experiment, and it will decrease the amount of times you have to turn the handle to produce an earthquake. For this model, the handle is $73 / 4$ inches long. Using the 4 pulley system means that changing the handle is not a necessity. 


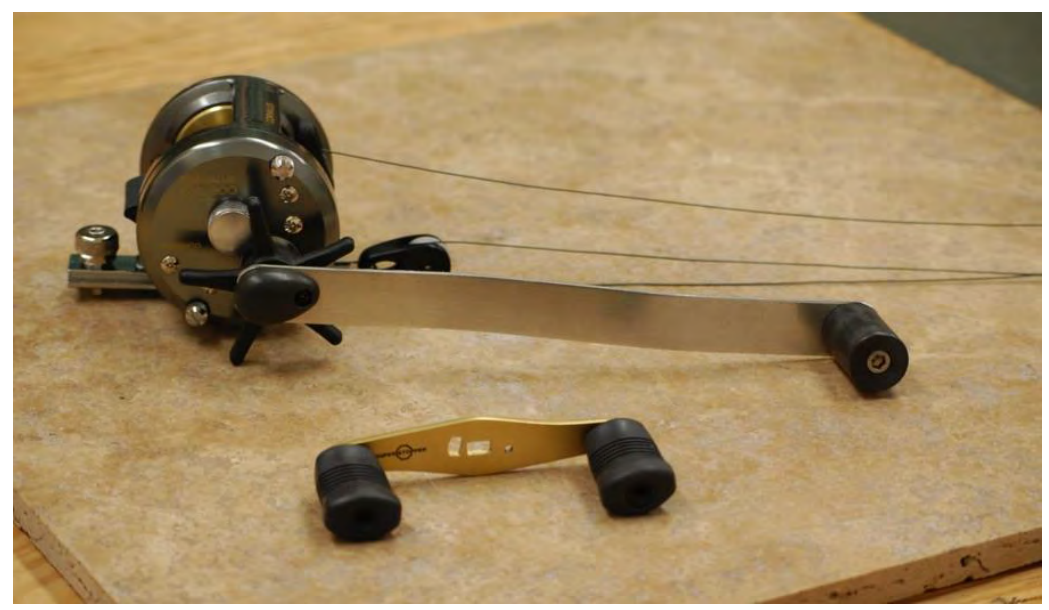

Photograph of custom 73/4-inch handle replaces Corvalus handle.

- Unscrew the handle on the Ronstan Series 19 Slide.

- Place reel on slide. Drill holes through reel's base in alignment with the slide's holes. Choose small screws to hold reel in place on slide. The screws cannot be too tall because it will be difficult to screw them in.

- Attach the reel to the slide.

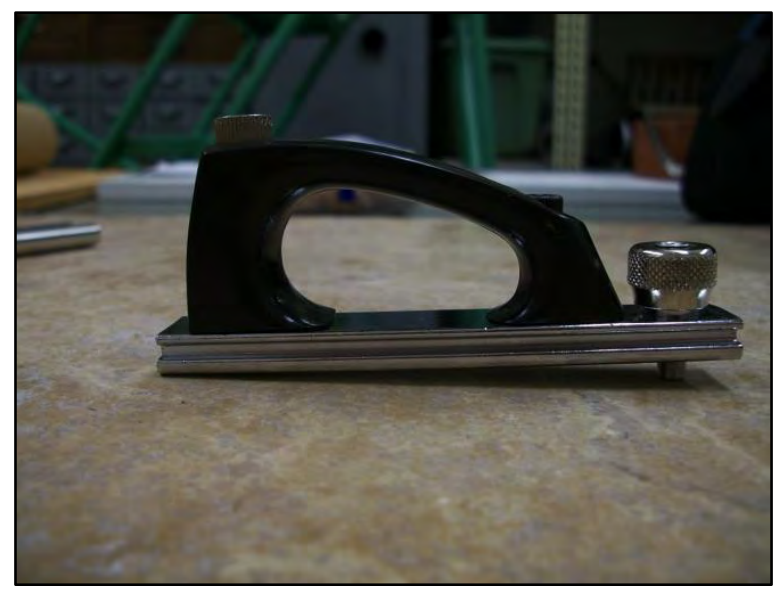

Photograph of Ronstan Series 19 spring-loaded track stop. Remove the handle.

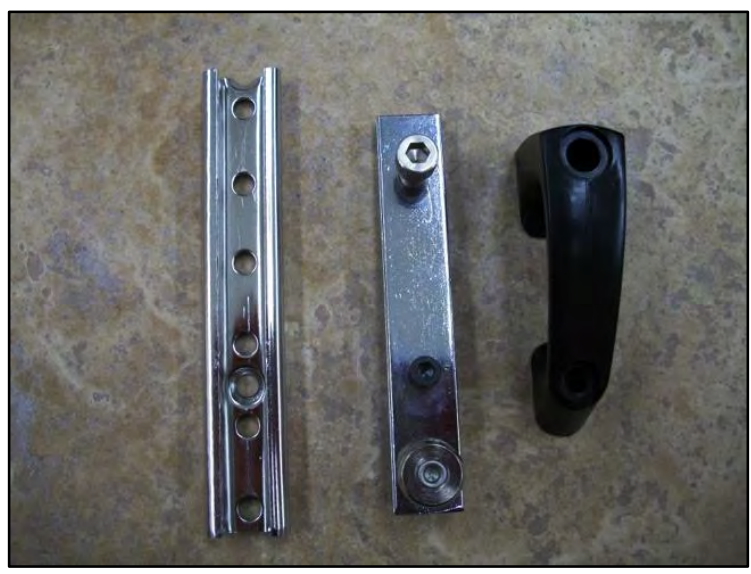


Photograph of Ronstan Series 19 Slide with Jib Sheet Fairlead and Spring-Loaded Track Stop. Handle is removed.

\section{Step 5}

- Attach fishing reel to foam board.

- Measure the furthest distance the reel can be placed from the tile's edge. Mark this point; the middle of the track will be placed here.

- Use a screw to attach the track to the plastic board using the large hole on the rack. It may be desirable to pre-drill the hole.

- Put two more screws at the front edges of the track to ensure the track will not wiggle side to side.

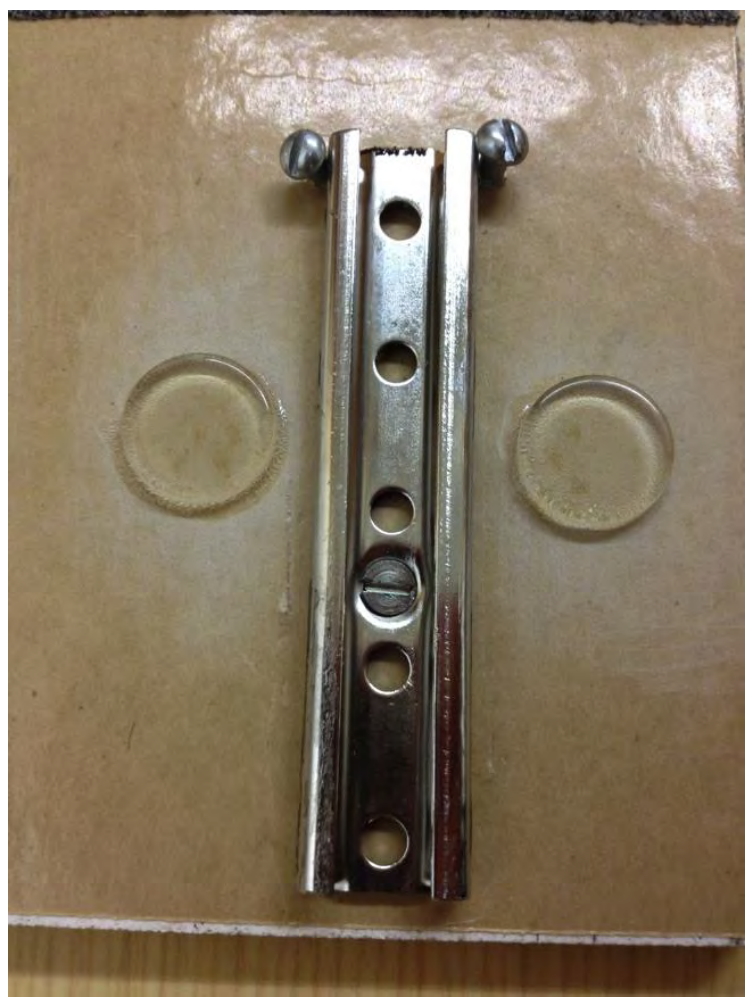

Photograph of slider track screwed to the plastic base. 


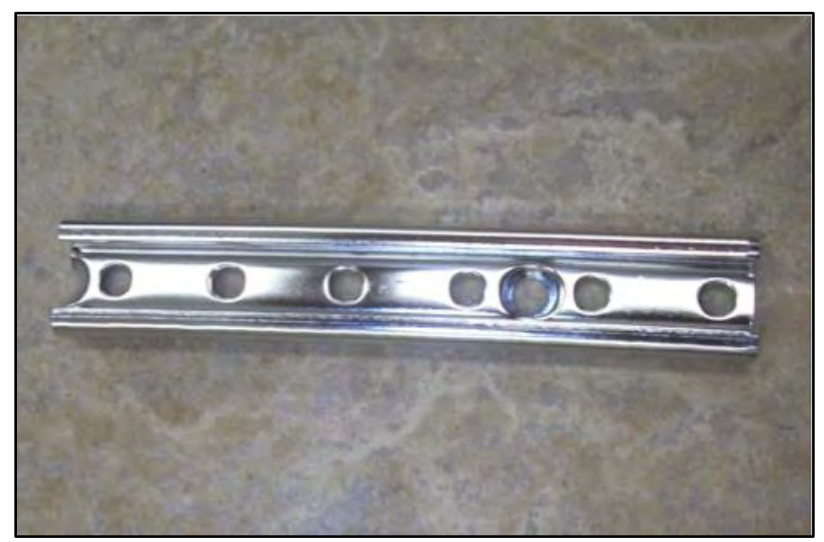

Photograph of front side of slider track.

\section{Step 6}

- After the track is securely in place, put a piece of rubber under each side of the reel to prevent it from wobbling.

- Slide the reel (now screwed onto the slider) onto the track (now adhered to the foam board) and lock it into place.

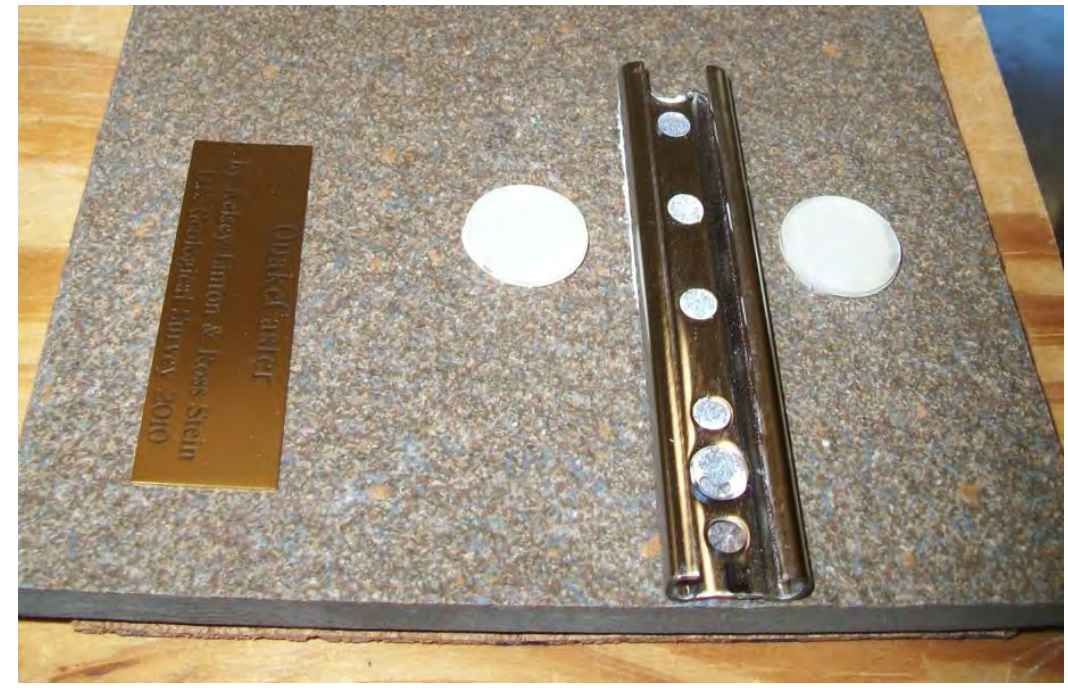

Photograph showing placement of rubber underneath the sides of the reel, which will be mounted on the track car.

\section{Step 7}

- Set up a pulley system to alleviate the weight you feel when turning the handle:

- Bend a thin metal wire at the bottom of the reel/slider to create an outline of a square. The metal wire can be attached to the front screw.

- Glue two of the kite pulleys together using the 4200 sealant or another strong adhesive (such as epoxy). Use a C-clamp to hold them in position for several hours to allow the glue to dry. 
- Before fully attaching the wire to the screw, add a pulley to the wire. Thread the spectra through the pulley. The Spectra is a low-stretch line. It is a trademark of Honeywell International. It is braided filaments of high-modulus material used in sailing and finishing lines. Spectra can be bought online.

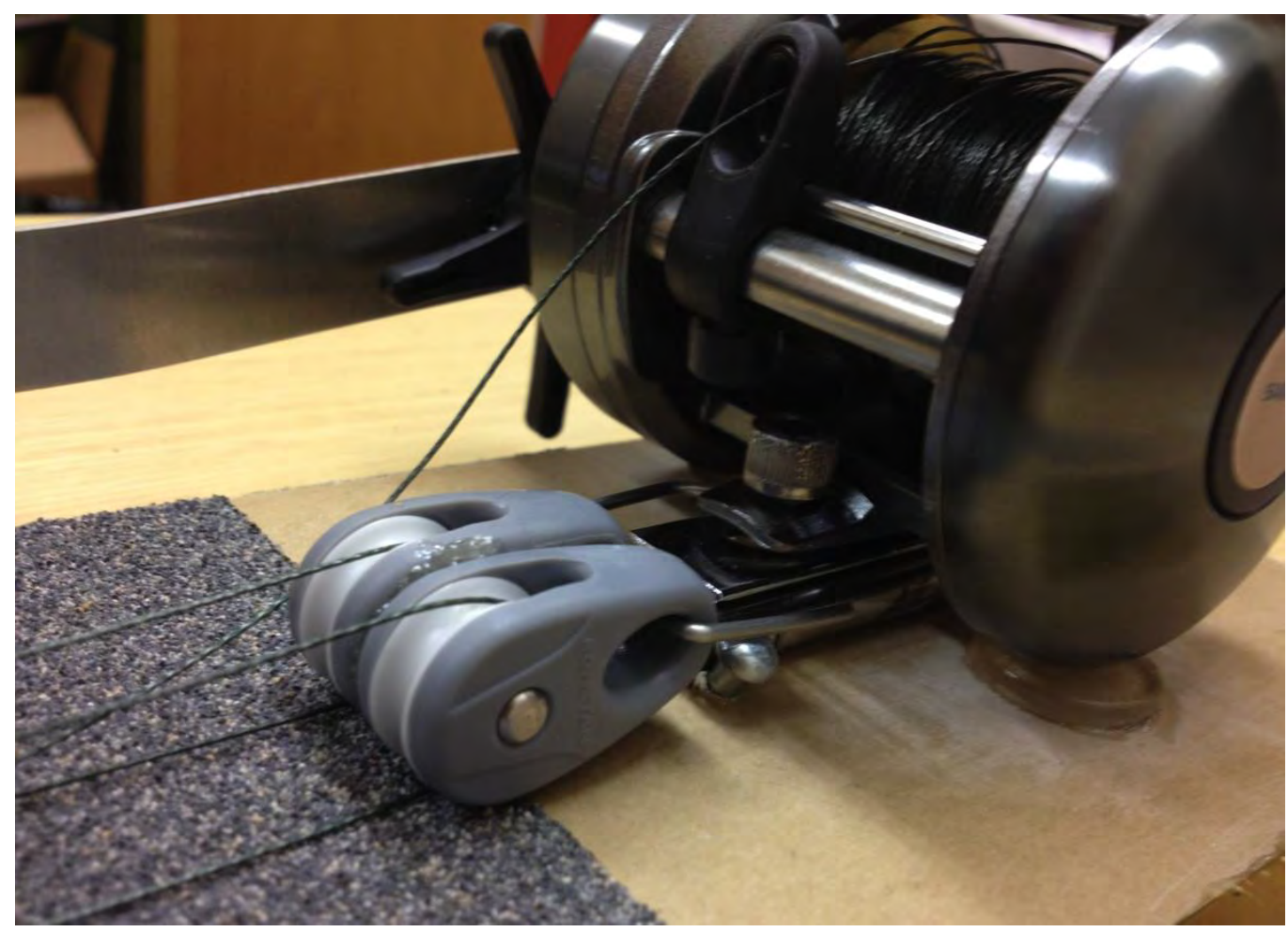

Photograph of Spectra line and pulley system.

- Continue to thread the spectra through the remaining pulleys; bring the spectra back towards the reel and then back toward the front pulley. Tie the spectra to the front pulley, ideally using a bowline knot. 


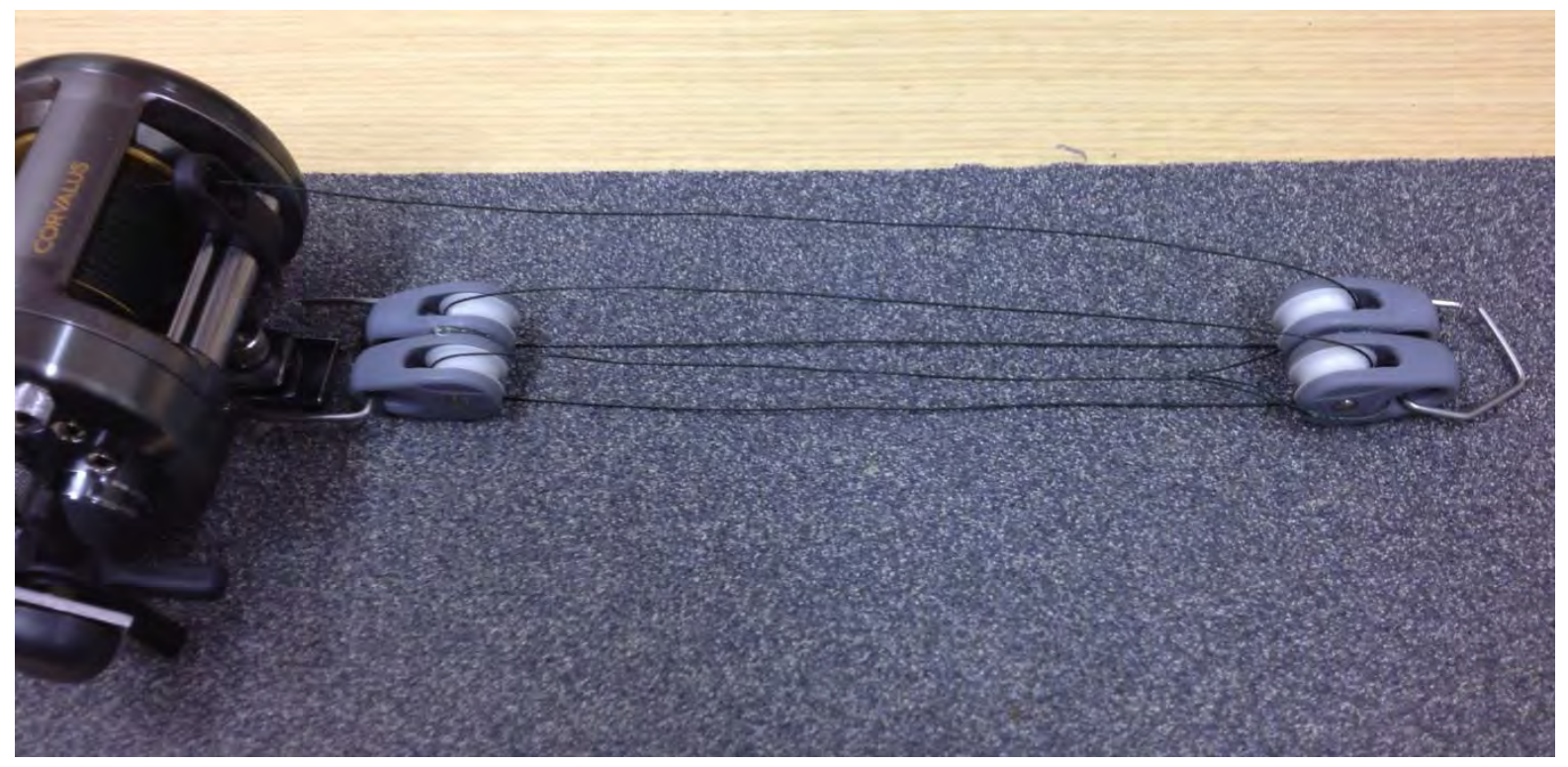

Photograph of pulley system, reduces the weight you feel when turning the handle.

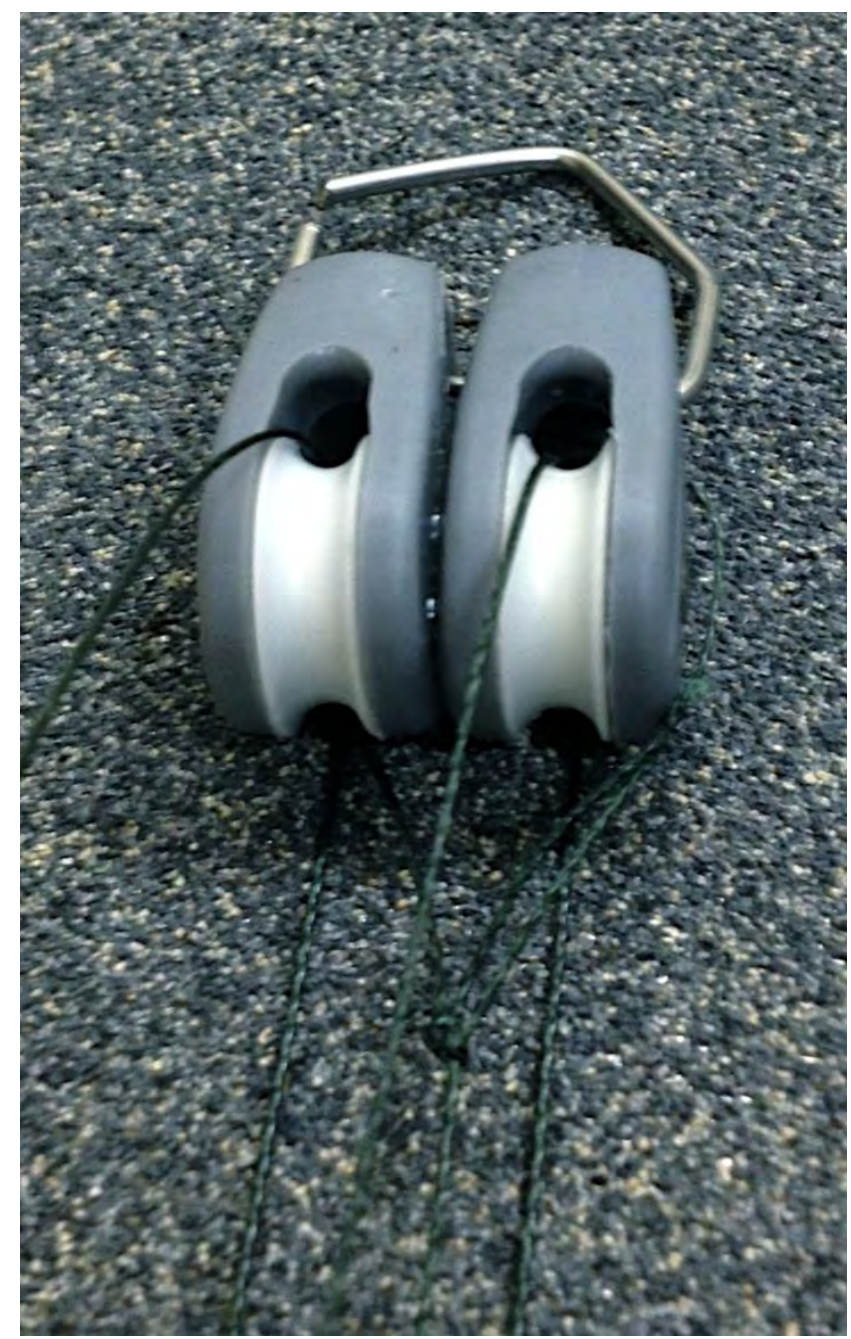

Photograph of front pulley. 


\section{Step 8}

- Add a layer of cork to the bottom of the nonskid-covered foam board.

- Lay out cork over bottom of foam board and, using an X-Acto knife, cut around the edges.

- Spray one side of the cork with Home Depot's spray-on adhesive and attach the cork to bottom of nonskid-covered foam board. Let dry.

\section{Step 9}

- Prepare the QuakeCaster for use:

- Attach a size 64 rubber band to a photo clip on a granite slider.

- Attach the Ohaus scale to the other end of the rubber band.

- Link the scale with the pulley.

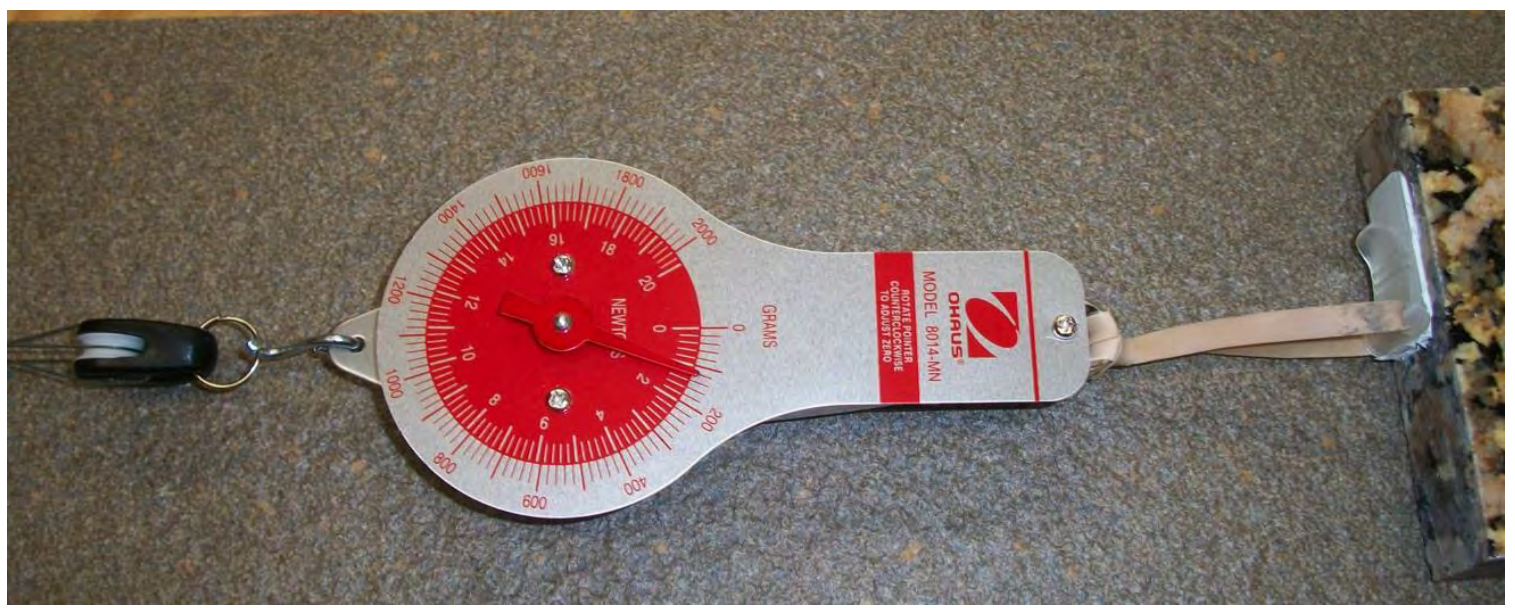

Photograph of pulley attached to Ohaus scale, which is attached to the granite slider.

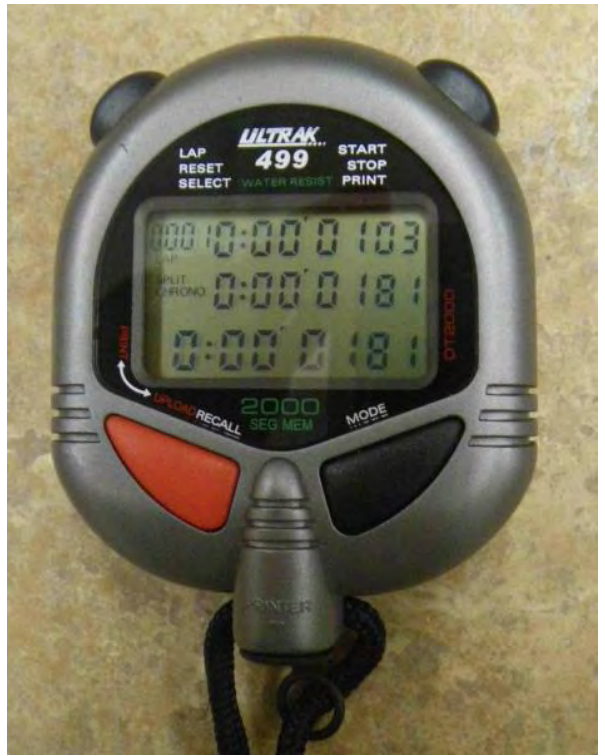


Photograph of stopwatch used to time quakes. Can store as many quake times in hundredths of seconds (both quake interval, top number, and cumulative times, middle number) as desired, and then these can be scrolled through or downloaded to a personal computer.

\section{Transport of QuakeCaster}
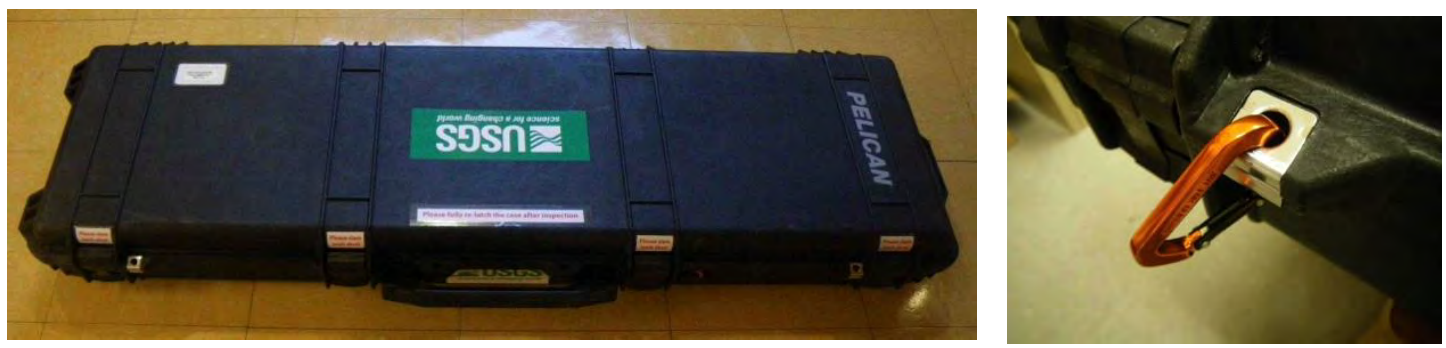

Photograph of Pelican case 1750, which is designed for a shotgun, but fits QuakeCaster perfectly. It has integral rollers (left side) and an end handle (right side of case), which is great at airports. With all gear inside, it weighs $38 \mathrm{lb}$. We put small karabiners from REI in the metal holes to make sure the case latches do not come open in transit.

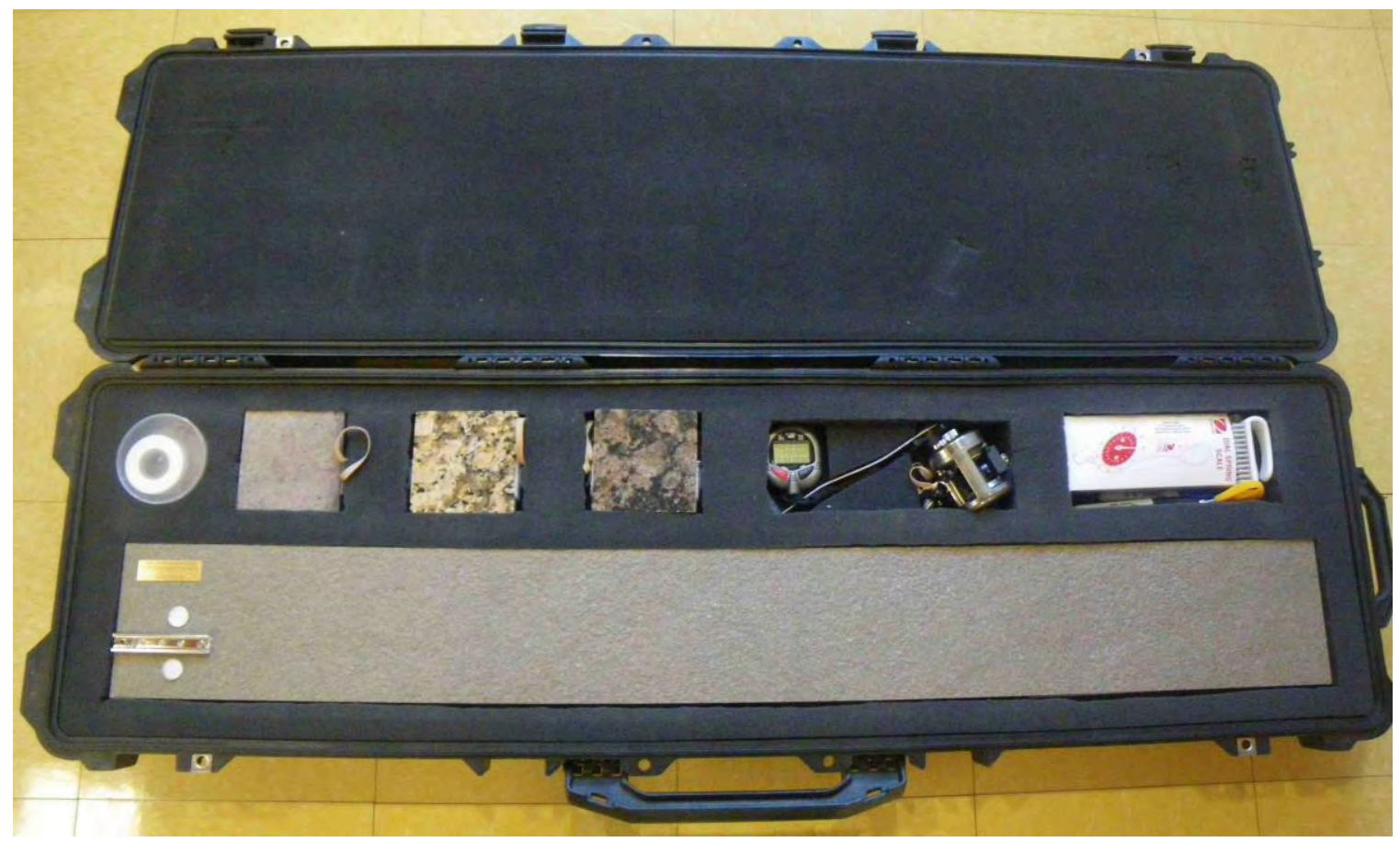

Photograph of Pelican case with foam recesses for all parts so QuakeCaster survives airline baggage handling and airport security inspections. We carry a few Sharpie marker pens, scissors, tape, lots of extra rubber bands, and extra carabiners, in the case. We also carry a small shoe brush (far right) to remove the fault gouge that forms on the sliding surface. 


\section{Parts and Costs for QuakeCaster}

[Note: Any use of trade, product, or firm names is for descriptive purposes only and does not imply endorsement by the U.S. Government]

This buying guide is based on locations nearest to the San Francisco Bay area, but most parts can be ordered online, and most cities offer the same services that we used.

\section{Total cost of parts is $\sim \mathbf{\$ 5 0 0 . 0 0}$}

\section{$48 \times 6$-inch sliding surface}

Tap Plastics

Foamed PVC board (cut to size), 1/8 inch thick-\$12.00

Web site: http://www.tapplastics.com/

McMaster-Carr

Abrasive anti-slip tape (amber) sandpaper roll 6" thick 10 yards (Product \#6970T261) $\$ 31.51$

Web site: http://www.mcmaster.com

\section{Granite sliders}

Marble City Company

Granite Samples-Free

Phone: 866-234-6896

Address: 611 Taylor Way \#6, San Carlos, CA 94070

Email: jhenderson@marblecitycompanyca.com

Web site: http://www.marblecityca.com

Any kitchen counter marble company has samples.

\section{Cutting granite sliders to $4 \times 4$ inches}

Sticks 'N' Stones

Granite Cutting-\$30.00

Phone: 650-592-9380

Dave Walter's Cell: 650-670-0116

Address: 947 Center Street, San Carlos, CA 94070

Email: stnst@sonic.net

Web site: http://www.sticksnstonesinc.net

Any granite cutting company can cut the $4 \times 4$-inch sliders.

\section{Sandblasting granite sliders}

Precision Powder Coating

Sandblasting-\$8 per tile

Phone: 650-631-6535

Address: 248 Harbor Blvd, Belmont, CA 94002

Any powder coating company will have a sand blaster. 
Fishing reel and marine adhesive sealant

West Marine

Corvalus 300 fishing reel-\$90.00

3 M 4200 Marine Adhesive Sealant—\$13.00

Web site: http://www.westmarine.com/

Ronstan Series 19 Slide with Jib Sheet Fairlead and Spring-Loaded Track Stop, CTrack Traveler System, and Plastic End Cap

Ronstan International, Inc.

Ronstan Series 19 Slide with Jib Sheet Fairlead and Spring-Loaded Track Stop

(RC81944)— $\$ 60.00$

Ronstan Series 19 C-Track Traveler System (RC8190-0.3)—\$15.00

Phone: 1-401-293-0596

Alan Prussia, Northern California rep's cell: 510-523-3600

Address: 45 High Point Avenue \#2, Portsmouth, RI 02871

Email: office@ronstan.us

Web site: http://www.ronstan.com/

\section{Pelican Case}

Pelican Products, Inc.

Pelican 1750 Long Case-\$220.00

Phone: 310-326-4700

Address: 23215 Early Avenue, Torrance, CA 90505

Email: sales@pelican.com

Web site: http://www.pelican.com/

\section{Extra foam for Pelican case}

Tallman's House of Foam

Extra foam for Pelican case- $\$ 14.00$

Phone: 650-327-4300

Address: 150 Hamilton Avenue, Palo Alto, CA 94301-1618

Web site: http://www.houseoffoam.net/

Any foam company can sell extra pieces of foam, or use leftover foam from the Pelican case.

\section{Ohaus Spring Scale}

Spring scale with clock face, 2 kilogram unit $(8014-M N)-\$ 26.00$

Tech support phone: 800-672-7722

Web site: http://us.ohaus.com/us/en/home/products/product-families/DIAL-US.aspx

Any spring scale will do, but it is helpful to have an easy-to-read scale.

Cork, spray-on adhesive, white electrical tape

Home Depot, Lowes, or Michaels

Cork glued to base of tile-\$10.00

Adhesive-\$10.00 
White electrical tape-\$4.00

Web site: http://www.homedepot.com

Any building supply store will have these materials.

Rubber bands, photo clips

Office Depot

Size 64 rubber bands-\$5.00

Photo clips - $\$ 4.00$

Web site: http://www.officedepot.com

Any office supply store will have these materials.

Stopwatch for recording a succession of quake times

Ultrak 499 stopwatch (can connect to a personal computer)— $\$ 68.75$

Fitzones/Stopwatchcentral, P.O. Box 1175, Galt, CA 95632

Web site: http://www.stopwatchcentral.com

\section{Load cells and indicator panels (not yet tried)}

Web site: http://www.lcmsystems.com/tension_load_cells.html 


\section{Appendix 2. How to Teach with QuakeCaster-A Lesson Plan for Middle School Classes or an Approach for High School or College Classes}

If you do all of the experiments below, then the learning session will likely span 2 to 3 classes. However, if you can do only the bulleted sections, then you can do it in one class. (Please also view the "How to Teach with QuakeCaster" 11-minute video.)

\section{Experiment 1-Tectonic Plates}

Show students a world map with labeled tectonic plates. Discuss plate motion. Explain what occurs at plate boundaries. (We have a "Plate Tectonic Puzzle" map that you can make at http://earthquake.usgs.gov/research/modeling/puzzle.php.)

Plates are stuck for hundreds of years and then suddenly jerk forward in earthquakes. Why does this happen? The answer, as formulated by Harry F. Reid in 1910 is that the Earth's crust is elastic - behaving like a very stiff slab of rubber sliding over a substrate of "honey"-like asthenosphere. The crust near the fault is deformed by the plate motion until the stress acting on the fault overcomes the frictional resistance and suddenly slips.

\section{Experiment 2-Earthquake Occurrence Hypotheses}

Ask students what they know about how scientists predict earthquakes. When is the next "big one?" How long has it been since the last earthquake?

Explain the four leading hypotheses that are used to try to predict earthquakes. Draw rough diagrams on the board.

Earthquakes are periodic. This means that the same amount of fault slip is separated by the same amount of time. There is some evidence for this, particularly in the study of the data of very small earthquakes on creeping faults.

Earthquakes are time-predictable. This means that the larger the amount of fault slip in the last earthquake, the longer the time until the next earthquake.

Earthquakes are slip-predictable. This means that the longer the time stress accumulates, the greater the amount of fault slip in the next earthquake.

Earthquakes occur randomly and have randomly varying size. This "Poisson" hypothesis is also widely used, particularly when little information about a fault and its past earthquakes is available.

Explain what it means to draw in best-fit lines for slip- and time-predictability. This can be done by eye or mathematically with the help of Google Documents.

What dos the slope represent? The long-term slip rate on the fault.

\section{Experiment 3-How QuakeCaster Elements Relate to Actual Faults and Earthquakes}

Show students QuakeCaster. Explain what each part of QuakeCaster represents in an actual fault. 
Fishing reel that steadily pulls in a line to simulate the steady plate tectonic motions far from the plate boundaries. Why is it important that the movement is steady in the experiment?

Granite slider(s) in frictional contact with a nonskid-covered foam board to simulate a fault at a plate boundary. Ask students why they think we put the slider's rough side down on the nonskid-covered foam board.

Rubber band connecting the line and the slider to simulate the elastic character of the Earth's crust.

Fault friction. Have students feel the texture of the granite sliders and nonskidcovered foam board.

\section{Experiment 4-Shear and Clamping Stress}

Explain what happens when you change the shear and clamping stress on a fault, when the fault is close to failure (the slider is just about ready to slide). Demonstrate this by using QuakeCaster.

To demonstrate increasing the shear stress, reel in QuakeCaster until two stacked sliders are on the verge of slipping. Now pull on the rubber band to trigger an earthquake.

To demonstrate decreasing the clamping stress, reel in QuakeCaster until two stacked sliders are on the verge of slipping. Now lift one slider to trigger an earthquake.

Both of these forces tend to bring the slider closer to failure. The higher the fault friction, the more important unclamping stress becomes.

\section{Two Stacked-Slider Earthquakes}

Ask students to observe the slider behavior during the experiment below. Let students make predictions about the slider behavior. Have students run QuakeCaster using two stacked sliders. Then ask for conclusions.

Did the slider behavior match students' predictions? Where the earthquake regular in time and size? (probably not). Why do you think this is true?

If the highly simplified QuakeCaster is not regular and periodic, the Earth must be even less so. This is what makes earthquake prediction so difficult.

\section{Experiment 5-Tests of Slip- and Time-Predictable Hypotheses}

Set up QuakeCaster with two stacked sliders. Place a piece of what electrical tape along the side of the nonskid-covered foam board. During this trial, one student reels at a constant rate (to simulate constant plate motion), one uses a marker pen to mark on the tape the slip distance after each earthquake, and one holds the stopwatch and records the time of each earthquake. 


\section{Plotting Results}

Transcribe the observations to a personal computer and plot the results. Then, project the results onto a whiteboard and annotate them. Here's how to plot them using Google Documents:

1. Open Google Documents.

2. Create new spreadsheet.

3. Label one column, "Time (second)" and another column "Cumulative Slip (cm)." These will be the $\mathrm{x}$ - and $\mathrm{y}$ - axis labels.

4. Choose "insert chart" and select "scatter plot."

5. Project the image onto whiteboard.

6. Using a whiteboard pen, draw in a stair-step diagram to connect data points.

7. Eyeball and then draw in best-fit lines for slip- and time-predictability (or these could be done using a personal computer), and let people assess them.

\section{Assessing Results}

Look at the slops for slip- and time-predictability. Which slope appears to be a better fit? What does the slope represent? (Look at the $\mathrm{x}$ - and $\mathrm{y}$-axes for help.) The slope is the fault slip rate.

Have students point out specific examples on the graph where data did not match the best-fit lines for hypotheses. Students can see why it is so difficult to accurately predict earthquakes.

\section{Calculating the RMS Misfit Value}

For each trial, high school and college students can calculate the root mean square (RMS) misfit value for each hypothesis, slip- and time-predictable, to see how the data compares to the hypotheses. Here's how to calculate the RMS misfit:

1. For each point, subtract the predicted slip distance from the observed slip distance.

2. Square each result.

3. Add all results together.

4. Divide total amount by the number of data points.

5. Take the square root of the result.

\section{Test of Constant Minimum versus Constant Failure Stress}

Set up QuakeCaster with two stacked sliders and attach a scale. Run QuakeCaster and let a few students come up to watch the dial. Run QuakeCaster again and let students predict at what force an earthquake will occur.

Comment that there is only partial stress drop after an earthquake. The force never goes to zero.

This is also true in almost all real earthquakes; the stress drop is $10-50$ percent of the

total stress. Why do students think that stress never decreased to zero?

During these trials, one student reels at a constant rate (to simulate constant plate motion), one records the force just before an earthquake, one records the force 
immediately after an earthquake, and one holds the stopwatch and records the time of each earthquake.

These results can also be plotted using a personal computer.

\section{One-Slider Earthquakes}

Ask students to observe the slider behavior during the experiments below. Let students make predictions about the slider behavior (frequency and time) in comparison to the two sliders' behavior. Have students run QuakeCaster using one slider. Then ask for conclusions. Did the slider behavior match students' predictions?

Were the earthquakes regular in time and size? (probably not). Did the slider slip the same amount each time? (probably not). Were they more or less frequent than the two stacked slider earthquakes? (probably twice as frequent). Were one-slider earthquakes larger or smaller than two stacked slider earthquakes? (probably half the slip).

Explain that smaller and more frequent earthquakes make sense, given that a force balance controls failure; The force resisting motion is now half what it was before. Explain that the same fault, for example, the San Andreas, can produce both "one-slider" (small) and "two-slider" (large) earthquakes even though the slip rate and friction are the same.

\section{Experiment 6-Foreshocks}

Explain foreshocks as the infrequent "short hops" before the actual large earthquake. Run QuakeCaster a few more times and ask students to observe.

Ask students if they saw any foreshocks (perhaps they will do so rarely, about 2 in every 5-10 earthquakes).

Comment that foreshocks are not reliable predictors of earthquakes because they don't always occur. In retrospect, about 2-5 percent of earthquakes are preceded by some kind of "foreshock," but they cannot be distinguished in advance.

\section{Experiment 7-Fault Gouge and Fault Friction}

Explain fault gouge, which will appear as a light dusting on the nonskid-covered foam board after running QuakeCaster a few times. Let students feel the gouge with their fingers.

The minerals Saponite and talc have been found in fault gouge within the San

Andreas Fault at the SAFOD drill site at the depth at which earthquakes occur. These minerals decrease friction within faults and could therefore be responsible for fault creep at shallower (saponite) and greater (talc) depths along the San Andreas.

Ask students to predict what would happen if fault gouge accumulated on the nonskid-covered foam board.

Would earthquakes be more or less frequent? (more) Bigger or smaller earthquakes? (smaller). The creeping section of the San Andreas produces the highest rate of very small earthquakes $(M<2)$ anywhere on the fault.

Set up QuakeCaster with granite sliders flipped over, so the smooth sides are in contact with the nonskid-covered foam board. Ask students to predict what will happen 
(much lower friction means more frequent and smaller quakes; it will almost appear to be fault creep).

Would earthquakes be more less frequent? Bigger or smaller earthquakes?

\section{Calculating the Coefficient of Friction}

High school and college students can calculate the coefficient of friction one of two ways. One option is to divide the force just before an event by the weight of the slider(s). A second option is to slowly tilt the tile, and then measure the angle between the table and the tile.

See if these two methods agree.

\section{Experiment 8-Sliders in Series}

Set up QuakeCaster with three sliders in series, representing a long fault with many sections. Ask students to wager which slider will slip first, second, third, and fourth. Have students run QuakeCaster and then ask for conclusions.

Did the sliders' behavior match students' predictions? What specific behavior did students see?

Were earthquakes regular in time and size? Did the sliders slip the same amount each time?

Give example of the North Anatolian sequence. 